Board of Governors of the Federal Reserve System

International Finance Discussion Papers

Number 1298

September 2020

\title{
Does Unemployment Risk Affect Business Cycle Dynamics?
}

Sebastian Graves

Please cite this paper as:

Graves, Sebastian (2020). "Does Unemployment Risk Affect Business Cycle Dynamics?," International Finance Discussion Papers 1298. Washington: Board of Governors of the Federal Reserve System, https://doi.org/10.17016/IFDP.2020.1298.

NOTE: International Finance Discussion Papers (IFDPs) are preliminary materials circulated to stimulate discussion and critical comment. The analysis and conclusions set forth are those of the authors and do not indicate concurrence by other members of the research staff or the Board of Governors. References in publications to the International Finance Discussion Papers Series (other than acknowledgement) should be cleared with the author(s) to protect the tentative character of these papers. Recent IFDPs are available on the Web at www.federalreserve.gov/pubs/ifdp/. This paper can be downloaded without charge from the Social Science Research Network electronic library at www.ssrn.com. 


\title{
Does Unemployment Risk Affect Business Cycle Dynamics?
}

\author{
Sebastian Graves*
}

August 14, 2020

\begin{abstract}
In this paper, I show that the decline in household consumption during unemployment spells depends on both liquid and illiquid asset positions. I also provide evidence that unemployment spells predict the withdrawal of illiquid assets, particularly when households have few liquid assets. Motivated by these findings, I embed endogenous unemployment risk in a two-asset heterogeneous-agent New Keynesian model. The model is consistent with the above evidence and provides a new propagation mechanism for aggregate shocks due to a flight-to-liquidity that occurs when unemployment risk rises. This mechanism implies that unemployment insurance plays an important role as an automatic stabilizer, particularly when monetary policy is constrained.
\end{abstract}

*Federal Reserve Board. Email: sebastian.h.graves@frb.gov. I am very grateful to Simon Gilchrist, Mark Gertler, and Thomas Sargent for their advice and support throughout this project. I would also like to thank Corina Boar, Jaroslav Borovička, Katarína Borovičková, William Gamber, Nils Gornemann and Virgiliu Midrigan for helpful discussions, as well as seminar participants at NYU, the Federal Reserve Board, and Washington University in St. Louis. The views expressed in this paper are solely those of the author and should not be interpreted as reflecting the views of the Board of Governors of the Federal Reserve System or any other person associated with the Federal Reserve System. 


\section{Introduction}

Unemployment spells are the largest source of income risk that households face. Yet the majority of household wealth is held in illiquid assets, which are not well suited to smoothing consumption during unemployment. In this paper I study the implications of these facts in a model with endogenous unemployment risk in which households trade both liquid and illiquid assets. The model provides a new propagation mechanism for aggregate shocks, driven by a flight-to-liquidity that occurs when households face higher unemployment risk. It also suggests that an important role for unemployment insurance is its ability to dampen this amplification by lessening the cyclicality of household income risk.

I begin by presenting new empirical evidence on the relationship between unemployment, the liquidity of asset holdings, and consumption. Using data from the Consumer Expenditure Survey and the Panel Study of Income Dynamics, I show that the decline in consumption that households experience during unemployment spells depends on both their liquid and illiquid asset positions. In particular, the decline is smallest for households with significant liquid asset holdings, larger for households with only illiquid assets, and largest for households with few assets of either type. ${ }^{1}$ This finding suggests that households with illiquid wealth are at least partially able to use such assets to smooth their consumption during unemployment. I use data from the Survey of Consumer Finances to confirm that this is the case: I show that households that experience an unemployment spell are more likely to make a withdrawal from their illiquid asset holdings than those that do not, and that this effect is stronger when the unemployment spell is long or when households have few liquid assets.

Motivated by this empirical evidence, I study a heterogeneous-agent New Keynesian (HANK) model in which households trade both liquid bonds and illiquid capital and are subject to endogenous unemployment risk due to search frictions in the labor market. First, I show that this model is consistent with the above findings. I then study the response of the economy to aggregate shocks in order to answer the following questions: How does household demand for liquid and illiquid assets change when unemployment risk rises? Does this affect business cycle dynamics? Do policies that mitigate income risk, such as unemployment insurance, play an important role as automatic stabilizers?

\footnotetext{
${ }^{1}$ In the terminology of Greg Kaplan, Giovanni L. Violante and Justin Weidner (2014), the first group are non hand-to-mouth households, the second are the wealthy hand-to-mouth, and the third are the poor hand-to-mouth.
} 
I find that the interaction of illiquid assets and endogenous unemployment risk provides a novel propagation mechanism for aggregate shocks. Higher unemployment risk triggers a flight-to-liquidity: households increase their demand for liquid assets as these are the best suited to smoothing consumption during unemployment spells. Conversely, demand for illiquid capital declines. In the presence of sticky prices, this decline in investment leads to lower output and higher unemployment, prompting a feedback loop between unemployment risk and aggregate demand. A key feature of the model is that income risk responds endogenously to aggregate shocks through changes in the unemployment rate. I use the Current Population Survey to show that this is confirmed in the data: the cyclicality of income risk is driven entirely by changes in unemployment risk. ${ }^{2}$

If there is no unemployment insurance, this propagation mechanism implies that the response of unemployment or output is around 35\% larger than in a version of the model with no idiosyncratic unemployment risk. Unemployment insurance provides a source of consumption smoothing during unemployment spells, and consequently dampens the flight-to-liquidity and the feedback loop between unemployment risk and aggregate demand. Quantitatively, I find that unemployment insurance removes around half of the amplification that the flightto-liquidity mechanism provides. Unemployment insurance is even more important when monetary policy is constrained, as the feedback loop between unemployment risk and aggregate demand is significantly strengthened at such times, an implication that seems particularly relevant given that nominal interest rates have recently returned to the zero lower bound in almost all advanced economies due to the COVID-19 pandemic.

In the final section, I compare the results from this two-asset model to those from a model where households have access to one liquid asset. Without the flight-to-liquidity and decline in investment demand that occurs in the two-asset model, unemployment risk and unemployment insurance have no effect on business cycle volatility. It is well known that a model with both liquid and illiquid assets can generate a large number of households with high marginal propensities to consume. However, critics have argued that the same end can be achieved in simpler one-asset models which are calibrated to match moments of the liquid (rather than total) wealth distribution. In this paper, I show that the presence of liquid and illiquid assets also crucially affects the answers to questions about how unemployment risk affects business cycle dynamics.

\footnotetext{
${ }^{2}$ Fatih Guvenen, Serdar Ozkan and Jae Song (2014) use Social Security Administration data to show that the skewness of the income growth distribution is strongly pro-cyclical. The role of unemployment cannot be studied in their data as it does not include a measure of time spent employed.
} 


\subsection{Literature Review}

The empirical evidence on the consumption response to unemployment spells in this paper builds on previous work by Jonathan Gruber (1997), Mark Aguiar and Erik Hurst (2005), Gabriel Chodorow-Reich and Loukas Karabarbounis (2016), Jonas Kolsrud, Camille Landais, Peter Nilsson and Johannes Spinnewijn (2018) and others. These papers either estimate the average consumption decline during unemployment or focus on heterogeneity related only to liquid asset holdings. I provide evidence that illiquid asset holdings are also an important determinant of the response of household consumption to unemployment.

A number of recent papers have investigated the source of the pro-cyclical skewness of the income growth distribution documented by Guvenen, Ozkan and Song (2014). I use the Current Population Survey (CPS) to show that this is driven entirely by cyclicality in the distribution of changes in time employed. For workers that do not experience unemployment, the skewness of the income growth distribution exhibits no cyclicality. This is consistent with evidence from Italian data provided in Eran B. Hoffmann and Davide Malacrino (2019).

This paper also contributes to the literature studying the aggregate implications of unemployment risk in HANK models. Morten O. Ravn and Vincent Sterk (2017) study a one-asset model in which unemployment risk strongly amplifies business cycle fluctuations. The key difference between their model and the one-asset model in this paper is the assumption of autarky that they introduce. In particular, they assume that agents are unable to borrow and that bonds are in zero net supply, implying that all households must hold no assets in equilibrium. In Section 7, I show that unemployment risk has no effect on business cycle dynamics if agents are able to trade a liquid asset.

The lack of amplification in the one-asset model in this paper is consistent with the results of Nils Gornemann, Keith Kuester and Makoto Nakajima (2016). Their paper studies a one-asset model with unemployment risk and physical capital. In their model the increase in precautionary saving in response to a rise in unemployment risk raises the volatility of consumption but lowers the volatility of investment, leaving the volatility of output un-

changed. In contrast, if capital is illiquid, as in the two-asset model in this paper, the household response to higher unemployment risk does not smooth the response of investment, as households increase their demand only for liquid assets.

One paper that studies the role of unemployment risk in a two-asset setting is Wouter $\mathrm{J}$ 
Den Haan, Pontus Rendahl and Markus Riegler (2017). However, in their model both assets are liquid, and there is no physical capital. ${ }^{3}$ Whether or not unemployment risk amplifies business cycles in their model depends crucially on the degree of nominal wage stickiness. The mechanism in my two-asset model relies on the presence of an illiquid asset and does not depend on the responsiveness of wages.

My paper also contributes to the recent literature on HANK models with both liquid and illiquid assets. Greg Kaplan, Benjamin Moll and Giovanni L Violante (2018) show that having a model where the majority of wealth is illiquid helps to generate a realistic distribution of marginal propensities to consume, and that this changes our understanding of the transmission mechanism of monetary policy. I incorporate labor market frictions into such a model in order to study the aggregate implications of unemployment risk.

The mechanism in the two-asset model in this paper is related to that studied by Christian Bayer, Ralph Lütticke, Lien Pham-Dao and Volker Tjaden (2019). In a two-asset model with a competitive labor market, they show that uncertainty shocks to households' idiosyncratic productivity can lead to a decline in investment and output through a "wait-and-see" channel, similar to that studied by Nicholas Bloom (2009). The mechanism in their model is only operative in response to exogenous uncertainty shocks to idiosyncratic productivity. In this paper, income risk is endogenous as any shock that affects the unemployment rate also affects household income risk. The fact that income risk is endogenous is crucial for the propagation mechanism in this paper: if income risk is exogenous there is no feedback loop between income risk and aggregate demand.

Finally, this paper contributes to the literature studying the role of unemployment insurance as an automatic stabilizer, such as Rohan Kekre (2016) and Alisdair McKay and Ricardo Reis (2016b). The latter paper uses a one-asset HANK model and finds that automatic stabilizers have little effect on business cycle volatility when monetary policy is not constrained, as in the one-asset model studied in this paper. In contrast, my two-asset model suggests that unemployment insurance can affect business cycle volatility through its ability to dampen the flight-to-liquidity that occurs when unemployment rises. The rest of the paper is organized as follows. Section 2 shows that the consumption response to unemployment spells depends on both liquid and illiquid asset holdings. Section 3 documents the relationship between unemployment and the withdrawal of illiquid assets. Section 4 describes the twoasset model and Section 5 shows that it is consistent with the empirical evidence. Section

\footnotetext{
${ }^{3}$ The two assets in their model are bonds and equity in the firms that post vacancies in the labor market.
} 
6 studies the impact of an aggregate productivity shock in different versions of the twoasset model. Section 7 compares these results with those from a one-asset model. Section 8 concludes.

\section{Consumption Response to Unemployment Spells}

In this section I show that the decline in household consumption during unemployment spells depends both on liquid and illiquid asset positions.

Methodology As in Kaplan, Violante and Weidner (2014), I classify households as non hand-to-mouth if they have significant liquid asset holdings, wealthy hand-to-mouth if they have few liquid assets but significant illiquid asset holdings, and poor hand-to-mouth if they have few liquid or illiquid assets. I then estimate the response of consumption to unemployment spells using the following specification:

$$
\log C_{i, t}=\boldsymbol{\beta} \boldsymbol{X}_{\boldsymbol{i}, \boldsymbol{t}}+\gamma_{N} U_{i, t} \mathbb{1}\{\mathrm{N}-\mathrm{HTM}\}+\gamma_{W} U_{i, t} \mathbb{1}\{\mathrm{W}-\mathrm{HTM}\}+\gamma_{P} U_{i, t} \mathbb{1}\{\mathrm{P}-\mathrm{HTM}\}+\epsilon_{i, t}
$$

where $C_{i, t}$ denotes household consumption, $\boldsymbol{X}_{\boldsymbol{i}, \boldsymbol{t}}$ is a vector of control variables, and $U_{i, t} \in$ $[0,1]$ denotes the fraction of the year that the household spent unemployed. The indicator variables denote the liquid/illiquid asset status of the household. The coefficients $\gamma_{N}, \gamma_{W}$, and $\gamma_{P}$ measure the decline in log consumption during unemployment for households that are either non-hand-to-mouth, wealthy-hand-to-mouth, or poor-hand-to-mouth. Using this specification to identify the consumption decline during unemployment relies on the assumption that the set of control variables is large enough to eliminate any omitted variable bias coming from a correlation between unemployment spells and unobservables. As a crosscheck, I estimate the following panel regressions based on within-household variation in consumption: ${ }^{4}$

$$
\log \Delta C_{i, t}=\alpha_{t}+\gamma_{N} \Delta U_{i, t} \mathbb{1}\{\mathrm{N}-\mathrm{HTM}\}+\gamma_{W} \Delta U_{i, t} \mathbb{1}\{\mathrm{W}-\mathrm{HTM}\}+\gamma_{P} \Delta U_{i, t} \mathbb{1}\{\mathrm{P}-\mathrm{HTM}\}+\Delta \epsilon_{i, t}
$$

Data To estimate equation 2.1, I use data from the Consumer Expenditure Survey (CEX)

\footnotetext{
${ }^{4}$ Chodorow-Reich and Karabarbounis (2016) use the same two specifications to estimate the average consumption response to unemployment spells, without conditioning on household's asset positions.
} 
for the period from 1996 to 2017, restricting the sample to households whose head is between the ages of 25 and 55. I measure consumption spending on non-durables and services by excluding spending on automobiles, housing, health expenses, and education. The CEX measures liquid asset holdings well, but has little information on illiquid asset holdings. I therefore use home-ownership as a proxy for positive illiquid asset holdings. ${ }^{5}$ I define households as hand-to-mouth if they are in the bottom $50 \%$ of the liquid asset distribution in a given year. ${ }^{6}$ I then define them as wealthy hand-to-mouth if they are also homeowners, and as poor hand-to-mouth if they are not.

To estimate equation 2.2, I use data from the Panel Study of Income Dynamics (PSID) for the period from 2005 to 2017. As in the CEX, I restrict the sample to households whose head is between the ages of 25 and 55. As well as having a shorter sample than the CEX, the PSID also includes less information on consumption: the measure I use is spending on food, clothing, recreation and vacations. On the other hand, the PSID does have more accurate information on illiquid wealth holdings: I measure illiquid wealth as housing equity plus the value of retirement accounts. Appendices A.1 and A.2 contains further details on the construction of the datasets.

Results The results of estimating equations 2.1 and 2.2 are shown in Table 1 . The estimated consumption declines are very similar using both the cross-sectional variation in the CEX and the within-household variation in the PSID. Columns 1 and 4 show estimates of the average response of consumption to unemployment without interacting unemployment with the asset indicator variables. I find that on average consumption is $20-25 \%$ lower during unemployment, in line with previous estimates. ${ }^{7}$

Columns 2 and 5 show the estimates when I split households only on the basis of their liquid asset holdings. The estimated consumption decline during unemployment is strongly influenced by a household's liquid asset position. Non hand-to-mouth households are able to use their liquid assets to smooth consumption during unemployment, and their consumption

\footnotetext{
${ }^{5}$ In Appendix B I use data from the Survey of Consumer Finances to show that home-ownership is a good proxy for illiquid asset holdings.

${ }^{6}$ Kaplan, Moll and Violante (2018) report that $15 \%$ of households have negative liquid asset holdings and a further $30 \%$ of households have liquid asset holdings close to zero.

${ }^{7} \mathrm{~A}$ large literature has studied the average response of consumption to unemployment. Chodorow-Reich and Karabarbounis (2016) find similar estimates in both the CEX and PSID. Aguiar and Hurst (2005) use the Continuing Survey of Food Intake of Individuals (CSFII) to estimate that food expenditure falls by $19 \%$ during unemployment.
} 


\section{Table 1: Consumption Response to Unemployment Spells}

\begin{tabular}{|c|c|c|c|c|c|c|}
\hline & \multicolumn{3}{|c|}{ CEX } & \multicolumn{3}{|c|}{ PSID } \\
\hline & (1) & (2) & (3) & (4) & (5) & (6) \\
\hline$U_{i, t}$ & $\begin{array}{c}-0.22 \\
(0.015)\end{array}$ & & & $\begin{array}{l}-0.26 \\
(0.051)\end{array}$ & & \\
\hline$U_{i, t} \mathbb{1}\{\mathrm{N}-\mathrm{HTM}\}$ & & $\begin{array}{c}-0.14 \\
(0.026)\end{array}$ & $\begin{array}{c}-0.14 \\
(0.026)\end{array}$ & & $\begin{array}{c}-0.14 \\
(0.069)\end{array}$ & $\begin{array}{c}-0.14 \\
(0.069)\end{array}$ \\
\hline$U_{i, t} \mathbb{1}\{\mathrm{HTM}\}$ & & $\begin{array}{c}-0.26 \\
(0.019)\end{array}$ & & & $\begin{array}{c}-0.32 \\
(0.065)\end{array}$ & \\
\hline$U_{i, t} \mathbb{1}\{\mathrm{W}-\mathrm{HTM}\}$ & & & $\begin{array}{c}-0.23 \\
(0.027)\end{array}$ & & & $\begin{array}{l}-0.28 \\
(0.131)\end{array}$ \\
\hline$U_{i, t} \mathbb{1}\{\mathrm{P}-\mathrm{HTM}\}$ & & & $\begin{array}{c}-0.30 \\
(0.026)\end{array}$ & & & $\begin{array}{c}-0.34 \\
(0.074)\end{array}$ \\
\hline$H 0: \gamma_{N}=\gamma_{H}$ & & 0.00 & & & 0.02 & \\
\hline$H 0: \gamma_{N}=\gamma_{W}=\gamma_{P}$ & & & 0.00 & & & 0.11 \\
\hline$H 0: \gamma_{W}=\gamma_{P}$ & & & 0.06 & & & 0.71 \\
\hline
\end{tabular}

Notes: Robust standard errors in parentheses. PSID standard errors are clustered by household head. Regressions weighted using sampling weights. Final three rows of the table report the p-values for different Wald tests. CEX uses 31638 observations from 1996-2017. PSID uses 17892 observations from 2005-2017.

declines by around $15 \%$ on average. Hand-to-mouth households are less able to smooth their consumption, which declines by $25-30 \%$ on average.

Columns 3 and 6 estimate the regressions in full, now splitting hand-to-mouth households into two groups on the basis of their illiquid asset holdings. When liquid asset holdings are low, illiquid asset holdings appear to significantly affect the consumption decline during unemployment: the consumption of poor hand-to-mouth households declines by at least $30 \%$, double the decline of non hand-to-mouth households. For the wealthy hand-to-mouth, the decline is around 25\%, suggesting that illiquid assets provide households with at least some ability to smooth consumption during unemployment.

To formally test the hypothesis that the size of the consumption decline depends on liquid and illiquid asset positions, Table 1 also reports the p-values of Wald tests that (1) the decline is the same for hand-to-mouth and non hand-to-mouth households, (2) the decline is the same for all three groups, and (3) that the decline for the hand-to-mouth does not depend on illiquid asset holdings. In the cross-sectional regressions using the CEX, all hypotheses can be rejected at the $10 \%$ level, confirming that both liquid and illiquid asset positions are 
important for determining the size of the consumption decline during unemployment. Due to the shorter sample in the PSID, the second and third hypothesis cannot be rejected in the regressions using within-household variation.

One concern with the approach used here is that differences in the consumption response to unemployment spells may reflect heterogeneity in the effect of unemployment spells on household labor income, rather than heterogeneity in the effect of a given decline in labor income on household consumption. In Appendix D I show that this is not the case: there is no evidence that the effect of a given unemployment spell on household labor income differs across the three groups.

\section{Illiquid Asset Response to Unemployment Spells}

The findings in the previous section suggest that illiquid assets can play a role in smoothing consumption during unemployment spells. I now turn to data from the Survey of Consumer Finances (SCF) to understand the relationship between unemployment spells and illiquid asset holdings. I find that unemployment is a strong predictor of illiquid asset withdrawal, and that this effect is stronger when the unemployment spell is long or when households have few liquid assets.

Data I use data from the SCF from 2004 to 2016. To measure the withdrawal of illiquid assets, I focus on early withdrawals from tax-deferred individual retirement accounts (IRAs). ${ }^{8}$ Such withdrawals are generally subject to a $10 \%$ penalty, making them a clear example of illiquid asset adjustment. ${ }^{9}$ Retirement accounts are an important component of household's illiquid asset holdings, making up around a fifth of all household wealth. I restrict the sample to households whose head is at most 55 years of age and has an IRA. More details on the sample are included in Appendix A.3.

Results Table 2 reports the probability of an early withdrawal for different groups of

\footnotetext{
${ }^{8}$ The SCF question about withdrawals from retirement accounts is specifically asked in relation to IRA/Keogh accounts, and does not relate to employer-sponsored accounts such as a 401(k).

${ }^{9}$ For Roth IRAs this penalty applies to earnings but not contributions. I obtain very similar results if I remove households with Roth IRAs from the sample.
} 
Table 2: Illiquid Asset Withdrawal Probabilities

\begin{tabular}{lccc} 
& Data & $95 \%$ C.I. & p-value \\
\hline Full Sample & 0.045 & $(0.037,0.053)$ & \\
\hline No Unemployment Spell & 0.038 & $(0.030,0.047)$ & \multirow{2}{*}{0.000} \\
Unemployment Spell & 0.106 & $(0.072,0.143)$ & \\
\hline Short Unemployment Spell & 0.062 & $(0.029,0.103)$ & \multirow{2}{*}{0.026} \\
Long Unemployment Spell & 0.157 & $(0.099,0.223)$ & \\
\hline Unemployment Spell \& Non-HTM & 0.066 & $(0.009,0.104)$ & \multirow{2}{*}{0.016} \\
Unemployment Spell \& HTM & 0.123 & $(0.085,0.193)$ & \\
\hline
\end{tabular}

Notes: Probabilities constructed using sampling weights from a sample of 4211 households from the 2004 to 2016 waves of the SCF. Bootstrapped confidence intervals in parentheses. p-values calculated using Fisher's exact test.

households. The first row shows that between four and five percent of households make an early withdrawal from their retirement account in a given year. The next two rows split the sample depending on whether or not the household head experienced an unemployment spell that year. Households whose head had an unemployment spell are almost three times as likely to have made an early withdrawal from their retirement account as those whose head was employed for the whole year. This provides evidence that the withdrawal of such illiquid assets is an important way that households smooth their consumption in the face of unemployment shocks.

Next, I further divide the sample of households whose head was unemployed into two groups, based on the length of the unemployment spell. Households whose head was unemployed for more than 12 weeks were more than twice as likely to make an early withdrawal than those whose head was unemployed for 12 weeks or less.

Finally, I split the sample of unemployed households based on their liquid asset holdings. As in Section 2, I define households as being hand-to-mouth if they are in the bottom 50\% of the liquid asset distribution. The last two rows of Table 2 show that households with low liquid asset holdings were around twice as likely to make an early withdrawal than those who had high liquid asset holdings if their head had an unemployment spell. Overall, these results are consistent with the idea that liquid assets are the primary source of consumption smoothing for unemployed households, but that illiquid assets are also used when households have depleted their liquid asset holdings. 
The second column of Table 2 provides bootstrapped confidence intervals for each of these probabilities, while the third column reports the p-value for tests that the probability of withdrawal does not depend on employment status, the length of the unemployment spell, or liquid asset holdings. In all cases, the null hypothesis that withdrawal probabilities are the same across the two groups can be rejected at the $5 \%$ level.

\section{Two-Asset Model}

Motivated by this empirical evidence, I now study the role of endogenous unemployment risk in a heterogeneous-agent New Keynesian model with both liquid and illiquid assets. As in Kaplan, Moll and Violante (2018), households trade both liquid assets (nominal bonds) and

illiquid assets (physical capital). ${ }^{10}$ Search frictions in the labor market render unemployment, and consequently income risk, endogenous to aggregate shocks.

In the model, households face a trade-off when choosing their asset portfolio. Bond holdings can be adjusted without cost, but offer a low rate of return. Capital offers a higher return, but is costly to adjust. As bonds are liquid, they are well suited to smoothing consumption in response to transitory income shocks, such as unemployment spells. The key mechanism in this model is that a household's optimal asset portfolio depends on the level of unemployment risk in the economy, leading to a time-varying preference for holding liquid assets.

Households Time is discrete. There is a continuum of infinitely-lived households that supply labor inelastically, derive utility from consumption, and trade both liquid and illiquid assets. Households' idiosyncratic labor productivity follows an exogenous Markov process. Households are also subject to shocks to their employment status. In each period, households that choose to adjust their illiquid asset position pay a random adjustment cost, described in more detail below. Within a period, the timing of events is shown in Figure 1.

For households that choose to adjust their illiquid asset holdings, the recursive problem is:

\footnotetext{
${ }^{10}$ In Section G.7, I show that the main result is not affected if the illiquid asset is housing rather than productive capital.
} 


\section{Figure 1: Model Timeline}

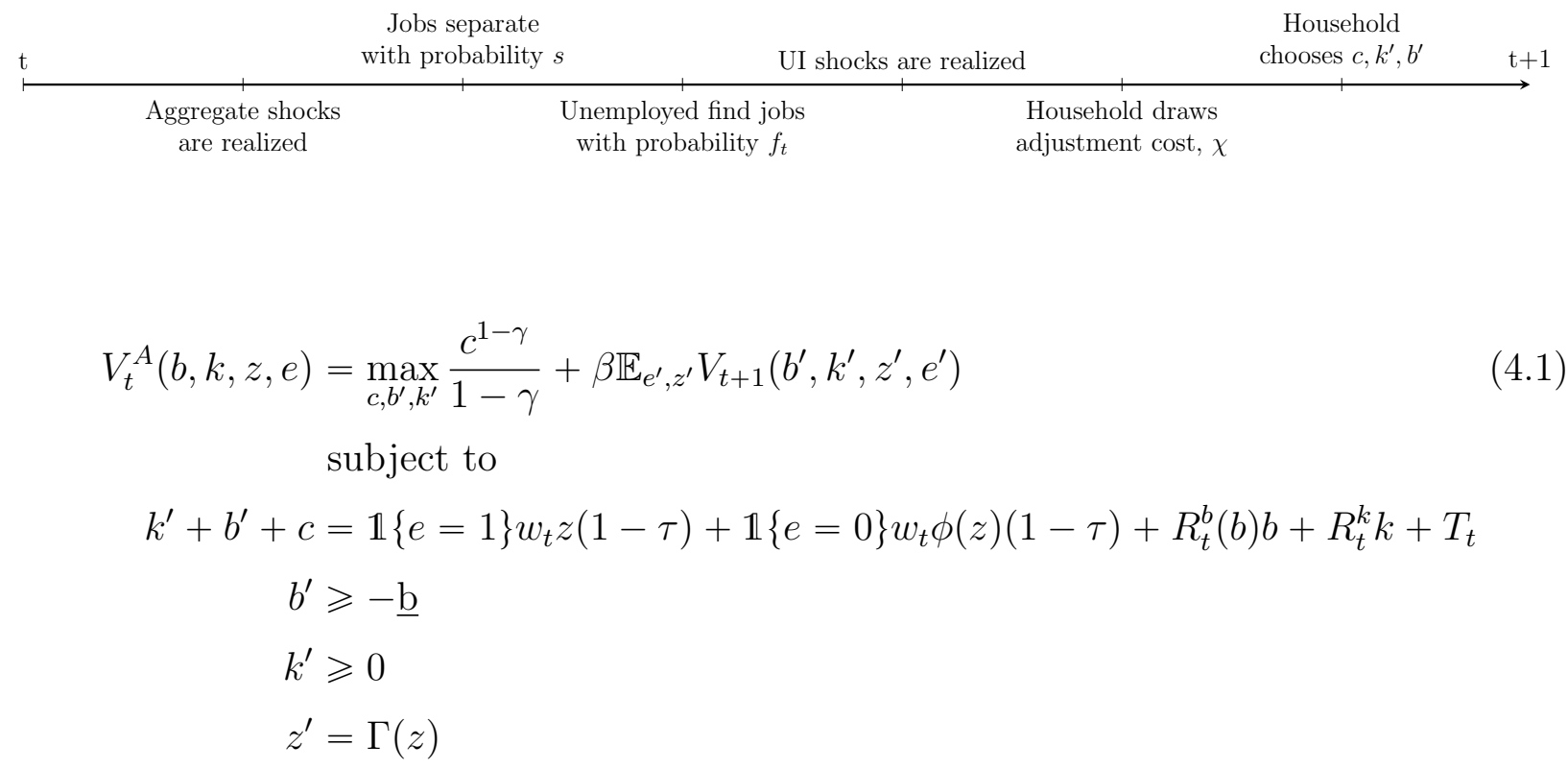

where $b$ denotes bond holdings, $z$ is the household's idiosyncratic productivity, and $e$ is the household's employment status, equal to 1 if employed, 0 if unemployed and receiving unemployment insurance, and -1 if unemployed and not receiving unemployment insurance. If employed, the household receives wage $w_{t}$ per unit of labor productivity. If unemployed and receiving unemployment insurance, households receive benefits equal to $w_{t} \phi(z)$. Both sources of labor income are subject to a linear tax, $\tau$. $T_{t}$ denotes a lump-sum transfer which is received by all households. ${ }^{11}$

Households face borrowing constraints on their holdings of both liquid and illiquid assets. Illiquid asset holdings must be non-negative. Household are able to borrow up to $\underline{b}$ units of the liquid asset. However, there is an exogenous wedge, $\kappa$, between the borrowing and lending rates on the liquid asset: ${ }^{12}$

$$
R^{b}(b)= \begin{cases}\frac{1+i_{t}}{\Pi_{t}} & \text { if } b \geqslant 0 \\ \frac{1+i_{t}}{\Pi_{t}}+\kappa & \text { if } b<0\end{cases}
$$

\footnotetext{
${ }^{11}$ This transfer is included primarily for computational reasons. It is chosen to be large enough that the lowest productivity household with no illiquid assets and liquid assets equal to $-\underline{b}$ is able to cover the interest payments on their liquid debt and still have a positive level of consumption.

${ }^{12}$ This assumption helps to ensure a realistic distribution of liquid asset holdings: a large mass of households with close to zero liquid assets, and a share of around $15 \%$ of households with negative liquid asset holdings.
} 
where $i_{t}$ is the nominal interest rate set by the central bank, and $\Pi_{t}$ is the gross rate of inflation. The return on the illiquid asset is derived from supplying capital services to the intermediate good producers at rate $r_{t}^{k}$. Capital services provided are the product of the utilization rate, $u_{t}$, and the household's holding of the illiquid asset, $k$. The rate of depreciation of capital is increasing in the utilization rate, as in Jeremy Greenwood, Zvi Hercowitz and Gregory W Huffman (1988). Thus, the rate of return on the illiquid asset is:

$$
R_{t}^{k}=1+r_{t}^{k} u_{t}-\delta_{0} u_{t}^{\delta_{1}}
$$

If the household doesn't adjust their illiquid asset holdings, their problem is:

$$
\begin{aligned}
V_{t}^{N A}(b, k, z, e) & =\max _{c, b^{\prime}} \frac{c^{1-\gamma}}{1-\gamma}+\beta \mathbb{E}_{z^{\prime}, e^{\prime}} V_{t+1}\left(b^{\prime}, k, z^{\prime}, e^{\prime}\right) \\
& \text { subject to } \\
k+b^{\prime}+c & =\mathbb{1}\{e=1\} w_{t} z(1-\tau)+\mathbb{1}\{e=0\} w_{t} \phi(z)(1-\tau)+R_{t}^{b}(b) b+R_{t}^{k} k+T_{t} \\
b^{\prime} & \geqslant-\underline{\mathrm{b}} \\
z^{\prime} & =\Gamma(z)
\end{aligned}
$$

Each period, household's draw an iid adjustment cost, $\chi$, from the uniform distribution on $[0, \bar{\chi}]$, denominated in units of utility. They then decide whether or not to adjust their capital holdings. Consequently, the value of the household's problem, conditional on a draw of $\chi$ is:

$$
V_{t}(b, k, z, e ; \chi)=\max \left\{V_{t}^{A}(b, k, z, e)-\chi, V_{t}^{N A}(b, k, z, e)\right\}
$$

The value before the draw of $\chi$ is:

$$
V_{t}(b, k, z, e)=\mathbb{E}_{\chi} V_{t}(b, k, z, e ; \chi)
$$

Idiosyncratic Shocks Households face idiosyncratic shocks to their employment status and to their productivity. Each period, employed households are separated to unemployment with exogenous probability $s$. Unemployed households find employment with endogenous probability $f_{t}$. If unemployed, the probability that households receive unemployment insurance is independent across periods and equal to $\xi{ }^{13}$ I assume that households whose

\footnotetext{
${ }^{13}$ I assume that recipiency is random as there is no evidence in the SCF that recipiency is related to liquid asset holdings: $48 \%$ of households that have unemployment spells report receiving unemployment insurance,
} 
employment is terminated may immediately re-enter employment.

Previous research has shown that having a realistic income process is crucial if models are to generate a realistic wealth distribution. A key feature of the data is the high level of kurtosis of the income growth distribution. By introducing infrequent large income changes, idiosyncratic unemployment risk helps to provide high kurtosis of income growth. However, to match the level seen in the data I also assume that idiosyncratic productivity shocks are infrequent. Specifically:

$$
\begin{aligned}
\log z^{\prime} & =\left(1-\rho_{z}\right) \mu_{z}+\rho_{z} \log z+\epsilon_{z} \\
\epsilon_{z} & = \begin{cases}N\left(0, \sigma_{z}^{2}\right) & \text { with prob } \lambda_{z} \\
0 & \text { with prob } 1-\lambda_{z}\end{cases}
\end{aligned}
$$

I introduce the normalization $\mu_{z}$ to ensure that the mean value of idiosyncratic productivity is equal to 1 .

Final Good Producers There is a representative final good producer, which aggregates a continuum of intermediate goods according to the production function:

$$
Y_{t}=\left(\int_{0}^{1} y_{j, t}^{\frac{\epsilon-1}{\epsilon}} d j\right)^{\frac{\epsilon}{\epsilon-1}}
$$

Their profit maximization problem leads to the following demand curve for intermediate goods:

$$
\begin{aligned}
y_{j, t}\left(p_{j, t}\right) & =\left(\frac{p_{j, t}}{P_{t}}\right)^{-\epsilon} Y_{t} \\
P_{t} & =\left(\int_{0}^{1} p_{j, t}^{1-\epsilon} d j\right)^{\frac{1}{1-\epsilon}}
\end{aligned}
$$

Intermediate Good Producers Intermediate goods are produced using both capital while the proportion is $50 \%$ for households with low liquid asset holdings and $45 \%$ for households with high liquid asset holdings. 
services, $k_{j, t}$, and labor, $n_{j, t}$, using the production function:

$$
y_{j, t}=A_{t} k_{j, t}^{\alpha} n_{j, t}^{1-\alpha}
$$

where $A_{t}$ is the level of aggregate productivity. Intermediate good producers rent capital from households at rate $r_{t}^{k}$ and labor from a representative labor agency at rate $h_{t}$. Their cost minimization problem implies the following value for their marginal cost of production:

$$
m_{t}=\frac{1}{A_{t}}\left(\frac{r_{t}^{k}}{\alpha}\right)^{\alpha}\left(\frac{h_{t}}{1-\alpha}\right)^{1-\alpha}
$$

I assume that intermediate good producers are owned by risk-neutral entrepreneurs who consume all profits each period. Price adjustment is subject to quadratic costs. ${ }^{14}$ Given these assumptions, the recursive form of their price-setting problem is:

$$
V_{t}^{I}\left(p_{j, t-1}\right)=\max _{p_{j, t}} Y_{t}\left\{\left(\frac{p_{j, t}}{P_{t}}-m_{t}\right)\left(\frac{p_{j, t}}{P_{t}}\right)^{-\epsilon}-\frac{\theta_{P}}{2} \log \left(\frac{p_{j, t}}{p_{j, t-1}}\right)^{2}\right\}+\beta V_{t+1}^{I}\left(p_{j, t}\right)
$$

where $\theta_{P}$ governs the size of price adjustment costs. The solution to this problem implies the following New Keynesian Phillips Curve:

$$
\log \left(\Pi_{t}\right)=\beta \frac{Y_{t+1}}{Y_{t}} \log \left(\Pi_{t+1}\right)+\frac{\epsilon}{\theta_{P}}\left(m_{t}-m^{*}\right)
$$

where $m^{*}=\frac{\epsilon-1}{\epsilon}$ is the inverse of the steady-state mark-up.

Labor Agency Intermediate good producers hire labor from a representative labor agency. This agency hires households in a frictional labor market by posting vacancies. I assume that the labor agency is also owned by risk-neutral entrepreneurs. The labor agency's recursive problem is:

$$
\begin{aligned}
& J_{t}(N)=\max _{N^{\prime}, V}\left(h_{t}-w_{t}\right) N^{\prime}-c V+\beta J_{t+1}\left(N^{\prime}\right) \\
& \quad \text { subject to } \\
& N^{\prime}=(1-s) N+q\left(\theta_{t}\right) V
\end{aligned}
$$

\footnotetext{
${ }^{14}$ As in Julio J Rotemberg (1982).
} 
where $N$ is the number of employed households, $V$ is the number of vacancies, $c$ is the cost of posting a vacancy, $q\left(\theta_{t}\right)$ is the job-filling probability, and $\theta_{t} \equiv \frac{V_{t}}{U_{t}}$ is labor market tightness.

There are two wages in the model: $h_{t}$ is the wage paid by intermediate good producers to the labor agency, and $w_{t}$ is the wage paid by the labor agency to employed households. Due to the search frictions in the model, there is a range of household wages that is between the reservation wages of households and the labor agency. I assume the following wage rule, which implies that the wage paid to households responds to the wage paid to the labor agency with elasticity $\epsilon_{w}:{ }^{15}$

$$
w_{t}=\bar{w}\left(\frac{h_{t}}{\bar{h}}\right)^{\epsilon_{w}}
$$

Labor Market The labor market is characterized by search and matching frictions. Given $U_{t}$ unemployed households and $V_{t}$ vacancies, $M\left(U_{t}, V_{t}\right)$ new employment relationships are formed according to the following matching function: ${ }^{16}$

$$
M\left(U_{t}, V_{t}\right)=\frac{U_{t} V_{t}}{\left(U_{t}^{l}+V_{t}^{l}\right)^{\frac{1}{l}}}
$$

The job-finding and job-filling rates are functions of labor market tightness:

$$
\begin{aligned}
& f\left(\theta_{t}\right)=\left(1+\theta_{t}^{-l}\right)^{-\frac{1}{l}} \\
& q\left(\theta_{t}\right)=\left(1+\theta_{t}^{l}\right)^{-\frac{1}{l}}
\end{aligned}
$$

Fiscal and Monetary Policy The central bank sets nominal interest rates according to the following Taylor rule:

$$
i_{t+1}=\bar{r}^{b}+\psi \log \left(\Pi_{t}\right)
$$

Unemployment insurance provides a replacement rate $\phi_{0}$ and is capped at a fraction $\phi_{1}$ of the average wage:

$$
\phi(z)=\min \left\{\phi_{0} z, \phi_{1}\right\}
$$

\footnotetext{
${ }^{15}$ The complexity of the problem precludes a Nash bargaining solution for wages. Similar wage rules are used in Gornemann, Kuester and Nakajima (2016) and Den Haan, Rendahl and Riegler (2017). In Appendix G.2, I show that the main results of the paper are robust to a wide range of values of $\epsilon_{w}$.

${ }^{16}$ As in Wouter J Den Haan, Garey Ramey and Joel Watson (2000). This matching function ensures that job-finding and job-filling rates are well defined for any value of $\theta_{t}>0$.
} 
The government taxes labor, distributes unemployment insurance and the lump-sum transfer, issues nominal bonds, and undertakes government spending. The government budget constraint is:

$$
G_{t}+r_{t}^{b} B_{t}^{g}+T_{t}+\xi\left(1-N_{t}\right) w_{t} \int \phi(z) d \mu_{t}=\tau N_{t} w_{t}+\tau \xi\left(1-N_{t}\right) w_{t} \int \phi(z) d \mu_{t}
$$

Equilibrium An equilibrium in this model consists of paths for household decision rules $\left\{c_{t}, b_{t}, k_{t}, u_{t}\right\}_{t=0}^{\infty}$, firm decision rules $\left\{L_{t}, K_{t}, N_{t}, V_{t}\right\}_{t=0}^{\infty}$, prices and returns $\left\{w_{t}, h_{t}, r_{t}^{b}, r_{t}^{k}\right\}_{t=0}^{\infty}$, inflation $\left\{\Pi_{t}\right\}_{t=0}^{\infty}$, the job finding rate $\left\{f_{t}\right\}_{t=0}^{\infty}$, fiscal variables $\left\{G_{t}, T_{t}, B_{t}\right\}_{t=0}^{\infty}$, and the distribution of households $\left\{\mu_{t}\right\}_{t=0}^{\infty}$ such that:

1. Decision rules solve household and firm problems, taking as given aggregate variables

2. The government budget constraint holds

3. The distribution satisfies aggregate consistency conditions

4. All markets clear

Market Clearing The following market clearing conditions must hold in equilibrium:

1. Bonds:

$$
B_{t}^{g}=B_{t}^{h}=\int b d \mu_{t}
$$

2. Capital:

$$
K_{t}=K_{t}^{h}=u_{t} \int k d \mu_{t}
$$

3. Labor:

$$
L_{t}=N_{t}=\int \mathbb{1}\{e=1\} d \mu_{t}
$$

4. Goods:

$$
Y_{t}=C_{t}+I_{t}+G_{t}+\Theta_{t}+\kappa \int \max \{-b, 0\} d \mu_{t}+c V_{t}
$$

The goods market clearing condition takes into account price adjustment costs, $\Theta_{t}$, as well as the borrowing costs and costs of posting vacancies. 


\subsection{Calibration}

Table 3 summarizes the calibration of the model. The model period is one quarter. Below I provide further details on the calibration process.

Labor Market The quarterly job separation rate is 0.1 , in line with the Job Openings and Labor Turnover Survey (JOLTS). I target a steady-state unemployment rate of 6\%, and a quarterly job-filling rate of 0.71, as in Den Haan, Ramey and Watson (2000). These values imply a matching function elasticity of $l=1.68$. I set the vacancy cost equal to $5 \%$ of the quarterly wage. Combined with the job-filling probability, this implies a hiring cost per worker of around $7 \%$ of the quarterly wage, as in Lawrence J Christiano, Martin S Eichenbaum and Mathias Trabandt (2016a). With this assumption, a steady-state wage of $\bar{w}=2.1$ is required to generate an unemployment rate of $6 \%$. I set the value of $\epsilon_{w}$ to 0.45, the elasticity of wages to labor productivity estimated by Marcus Hagedorn and Iourii Manovskii (2008). ${ }^{17}$

Income Process I set the values of $\rho_{Z}, \sigma_{Z}$, and $\lambda_{Z}$ in order to target the variance and kurtosis of the annual income growth distribution, as well as the variance of the level of income. Table 4 reports these moments in the model and the data. While the high kurtosis of the income growth distribution implies that idiosyncratic productivity shocks occur infrequently, unemployment spells provide income shocks that are both more frequent and more transitory.

Wealth Distribution The key parameters affecting the liquid and illiquid wealth distributions are the coefficient of relative risk aversion, the discount factor, the borrowing wedge, and the parameter governing the degree of illiquid asset adjustment costs. I set the coefficient of relative risk aversion, $\gamma$, to 2 . I calibrate the other parameters to target the total quantity of liquid and illiquid assets relative to output, as well as the fraction of households with negative liquid asset holdings. Table 4 provides various moments of the wealth distribution. The model also matches the share of hand-to-mouth households, defined as those with liquid

\footnotetext{
${ }^{17}$ Due to movements in the mark-up, this calibration leads to wages that are more responsive to labor productivity than in the data. This ensures that the results of the model are not driven by the stickiness of real wages, as further shown in Appendix G.2.
} 


\section{Figure 2: Low Recipiency of Unemployment Insurance}

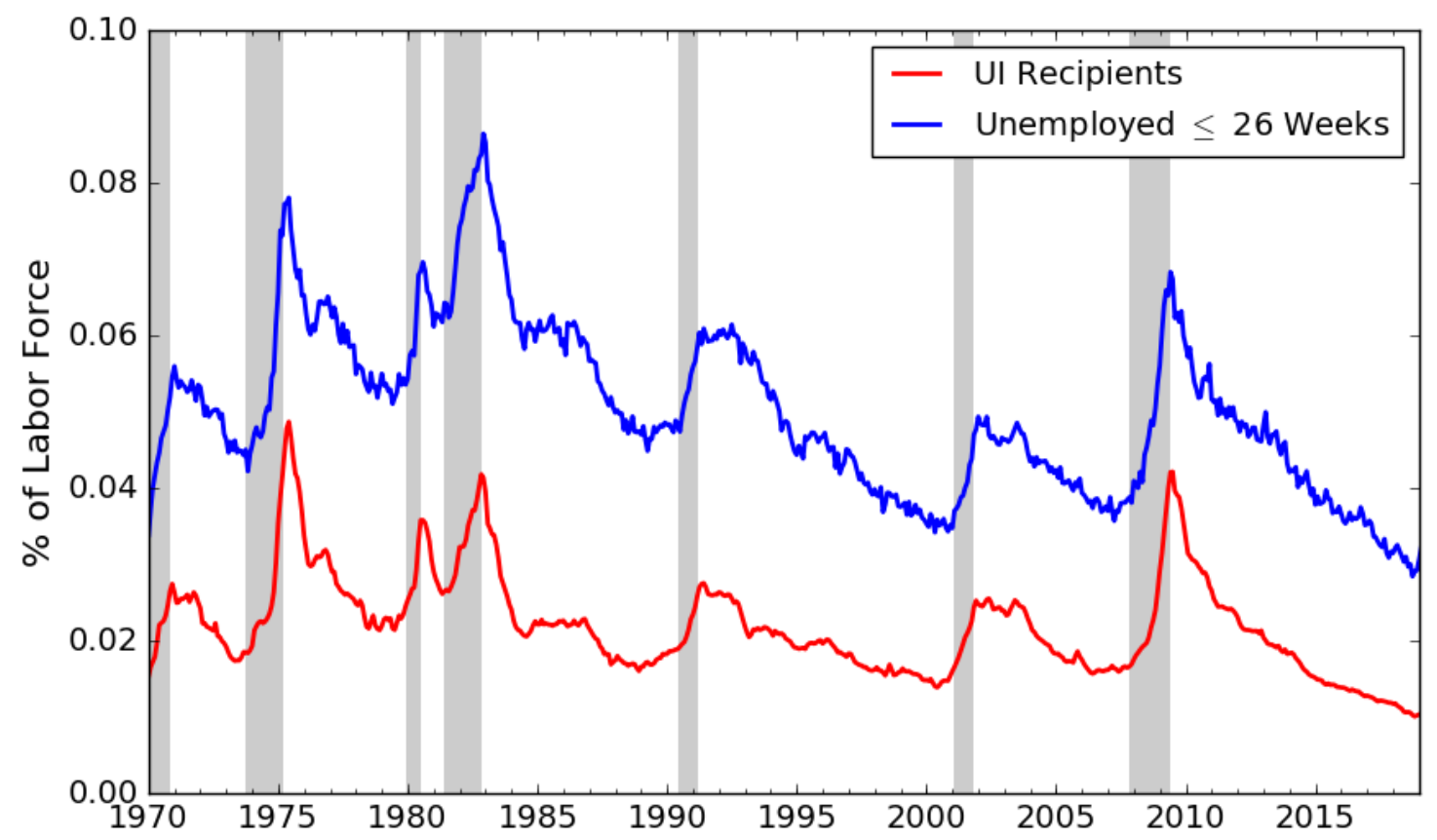

Notes: Data from the Bureau of Labor Statistics and the Employment and Training Administration.

asset holdings close to zero.

The model slightly under-predicts the Gini coefficient for total wealth inequality. The bottom two panels of Table 4 provide further details on the share of the liquid and illiquid wealth distributions held by different quantiles. The model fails to match the wealth holdings of the top $1 \%$ of households, and instead over-predicts the share of wealth held by the rest of the top $50 \%$ of the distribution. In terms of adjustment probabilities, $3.2 \%$ of employed households and $8.8 \%$ of unemployed households adjust their illiquid asset holdings each period. The total adjustment costs that households pay are equivalent to $0.9 \%$ of aggregate output. $^{18}$

Fiscal and Monetary Policy The particular details of unemployment insurance vary across US states. I set the cap on unemployment insurance, $\phi_{1}$, to two-thirds of the average wage, and the replacement rate, $\phi_{0}$, to $50 \%$. These values are the most common across states, as reported in Department of Labor (2018). The parameter $\xi$ governs the probability

\footnotetext{
${ }^{18}$ See Appendix F.4 for the derivation of this value. Kaplan, Moll and Violante (2018) report that illiquid asset adjustment costs in their model total less than $4 \%$ of GDP.
} 


\section{Table 3: Parameter Values}

\begin{tabular}{llll} 
Parameter & & Value & Source/Target \\
\hline Separation Rate & $s$ & 0.1 & JOLTS \\
Vacancy Cost & $c$ & 0.11 & $5 \%$ of Quarterly Wage \\
Steady-state Wage & $\bar{w}$ & 2.1 & 6\% Unemployment Rate \\
Wage Elasticity & $\epsilon_{w}$ & 0.2 & Elasticity of Wages to Labor Productivity \\
Matching Function Elasticity & $l$ & 1.68 & Quarterly Job-Filling Probability \\
Prod. Persistence & $\rho_{z}$ & 0.964 & Variance of Annual Income \\
Prod. Variance & $\sigma_{z}$ & 3.2 & Variance of Annual Income Growth \\
Prod. Shock Probability & $\lambda_{z}$ & 0.007 & Kurtosis of Annual Income Growth \\
\hline Risk Aversion & $\gamma$ & 2 & Standard \\
Discount Factor & $\beta$ & 0.975 & Illiquid Assets/Output \\
Adjustment Cost Limit & $\bar{\chi}$ & 2 & Liquid Assets/Output \\
Borrowing Limit & $\underline{\mathrm{b}}$ & 1 & 50\% of Average Quarterly Labor Income \\
Borrowing Wedge & $\kappa$ & 0.019 & \% Negative Liquid Assets \\
\hline UI Replacement Rate & $\phi_{0}$ & 0.5 & Department of Labor (2018) \\
UI Cap & $\phi_{1}$ & 0.67 & Department of Labor (2018) \\
UI Probability & $\xi$ & 0.45 & Employment \& Training Administration \\
Income Tax & $\tau$ & 0.3 & Kaplan, Moll and Violante (2018) \\
Transfer & $T$ & 0.15 & Computation \\
Return on Liquid Assets & $\bar{r}^{b}$ & 0.0025 & 1\% Annual Rate of Return \\
Taylor Rule Coefficient & $\psi$ & 1.5 & Kaplan, Moll and Violante (2018) \\
\hline Capital Share & $\alpha$ & 0.33 & Standard \\
Steady-State Depreciation Rate & $\delta_{0}$ & 0.014 & 6\% Annual Rate of Depreciation \\
Depreciation Elasticity & $\delta_{1}$ & 2.05 & Steady-State Utilization Rate of 1 \\
Elasticity of Substitution & $\epsilon$ & 20 & Mark-up of 5\% \\
Price Adjustment Cost & $\theta_{P}$ & 250 & Slope of New Keynesian Phillips Curve \\
\hline & & & \\
\hline
\end{tabular}




\section{Table 4: Income and Wealth Distributions}

\begin{tabular}{lcc} 
Moment & Data & Model \\
\hline Variance: Annual Log Earnings & 0.70 & 0.71 \\
Variance: 1-year change & 0.23 & 0.23 \\
Kurtosis: 1-year change & 17.8 & 18.5 \\
\hline Liquid Assets to Output & 0.26 & 0.27 \\
Illiquid Assets to Output & 2.86 & 2.84 \\
\% Poor Hand-to-Mouth & 0.1 & 0.07 \\
\% Wealthy Hand-to-Mouth & 0.2 & 0.23 \\
\% Negative Liquid Assets & 0.15 & 0.16 \\
Gini Coefficient (Total Wealth) & 0.81 & 0.73 \\
\hline Top 1\% share (Liquid) & 47 & 14 \\
Top 1\%-10\% share (Liquid) & 39 & 56 \\
Top 10\%-50\% share (Liquid) & 18 & 34 \\
Bottom 50\% share (Liquid) & -4 & -4 \\
\hline Top 1\% share (Illiquid) & 33 & 8 \\
Top 1\%-10\% share (Illiquid) & 37 & 43 \\
Top 10\%-50\% share (Illiquid) & 27 & 46 \\
Bottom 50\% share (Illiquid) & 3 & 2 \\
\hline
\end{tabular}

Notes: Data moments are from Fatih Guvenen, Fatih Karahan, Serdar Ozkan and Jae Song (2015) and Kaplan, Moll and Violante (2018). Moments from the model are calculated by simulating 1 million households until the steady-state of the model is reached, and aggregating income to an annual frequency. In the model I define household as hand-to-mouth if the absolute value of their liquid asset holdings is less than $10 \%$ of the average quarterly wage. 
that unemployed households receive unemployment insurance. Figure 2 shows that a large fraction of unemployed individuals do not actually receive unemployment insurance, even if their unemployment spell is short enough to qualify for benefits. I set $\xi$ equal to 0.45 , the average UI recipiency rate for the short-term unemployed. I set the linear income tax to $30 \%$, and the value of the transfer to 0.15 , equal to around $8 \%$ of the average wage. I set the steady-state real return on bonds to $1 \%$ on an annual basis. I assume that the Taylor rule coefficient on inflation is 1.5 .

Remaining Parameters I calibrate the remaining parameters of the model to standard values in the New Keynesian literature. The coefficient on capital in the intermediate good production function is set to 0.33 . I choose $\delta_{0}$ such that the depreciation rate on capital is $6 \%$ at an annual frequency and $\delta_{1}$ such that the steady-state utilization rate is equal to 1. I set the elasticity of substitution, $\epsilon$, to 20 , implying a steady-state mark-up of $5 \%$. I choose a low mark-up to ensure that profits are small, given that I assume that all profits are consumed by risk-neutral entrepreneurs. I then set the value of the price-adjustment cost, $\theta_{P}$, to 250 , which implies that the slope of the New-Keynesian Phillips curve is 0.08 . If price-adjustment was of the Calvo form, this would be equivalent to prices lasting four quarters on average.

\section{Model Validation}

Before turning to the effect of aggregate shocks in the model, I start by checking that the model is consistent with the empirical findings in Sections 2 and 3. To do this, I simulate a large panel of households in the steady-state of the model and aggregate to an annual frequency. Using this panel, I then run the same consumption regressions as in Section 2, and calculate illiquid asset withdrawal probabilities as in Section 3.

\subsection{Consumption Response to Unemployment Spells}

Table 5 compares the regression results in the model and the data. Column (4) shows that the average consumption decline during unemployment in the model is close to that estimated in the data. Columns (5) and (6) show that the model also matches the ranking seen in the data, 


\section{Table 5: Consumption Response to Unemployment Spells}

\begin{tabular}{|c|c|c|c|c|c|c|}
\hline & \multicolumn{3}{|c|}{ Data (CEX) } & \multicolumn{3}{|c|}{ Two-Asset Model } \\
\hline & (1) & (2) & (3) & (4) & (5) & (6) \\
\hline$U_{i, t}$ & $\begin{array}{c}-0.22 \\
(0.015)\end{array}$ & & & -0.19 & & \\
\hline$U_{i, t} \mathbb{1}\{\mathrm{N}-\mathrm{HTM}\}$ & & $\begin{array}{c}-0.14 \\
(0.026)\end{array}$ & $\begin{array}{c}-0.14 \\
(0.026)\end{array}$ & & -0.10 & -0.10 \\
\hline$U_{i, t} \mathbb{1}\{\mathrm{HTM}\}$ & & $\begin{array}{c}-0.26 \\
(0.019)\end{array}$ & & & -0.26 & \\
\hline$U_{i, t} \mathbb{1}\{\mathrm{W}-\mathrm{HTM}\}$ & & & $\begin{array}{c}-0.23 \\
(0.027)\end{array}$ & & & -0.21 \\
\hline$U_{i, t} \mathbb{1}\{\mathrm{P}-\mathrm{HTM}\}$ & & & $\begin{array}{l}-0.30 \\
(0.026)\end{array}$ & & & -0.30 \\
\hline
\end{tabular}

Notes: Robust standard errors in parentheses. Regressions weighted using CEX sampling weights, with 31638 observations from 1996 to 2017.

and almost exactly replicates the size of the consumption decline for both types of hand-tomouth households. The model fit is slightly worse for non hand-to-mouth households, for whom the consumption decline is a little lower in the model than the data.

To understand how the two-asset model generates these patterns, Figure 3 plots the log difference between the consumption of employed and unemployed households across the liquid and illiquid wealth distributions. ${ }^{19}$ The top panel shows the decline in consumption if the household does not adjust their illiquid asset holdings. The bottom panel shows the decline in consumption if they do adjust their illiquid asset holdings.

The top panel shows that liquid assets are the primary determinant of the consumption decline during unemployment for households that do not adjust their illiquid asset holdings. Thus, the consumption decline for wealthy hand-to-mouth households that do not adjust is similar to that of poor hand-to-mouth households. On the other hand, the bottom panel shows that if wealthy hand-to-mouth households do adjust their illiquid asset holdings, then the consumption decline during unemployment is negligible. The consumption decline during unemployment for this group is similar to that of non hand-to-mouth households.

The model is able to generate a realistic consumption decline for wealthy hand-to-mouth households because only a fraction of wealthy hand-to-mouth households choose to liqui-

\footnotetext{
${ }^{19}$ This is shown at the median level of productivity.
} 


\section{Figure 3: Consumption Declines and Illiquid Asset Adjustment}

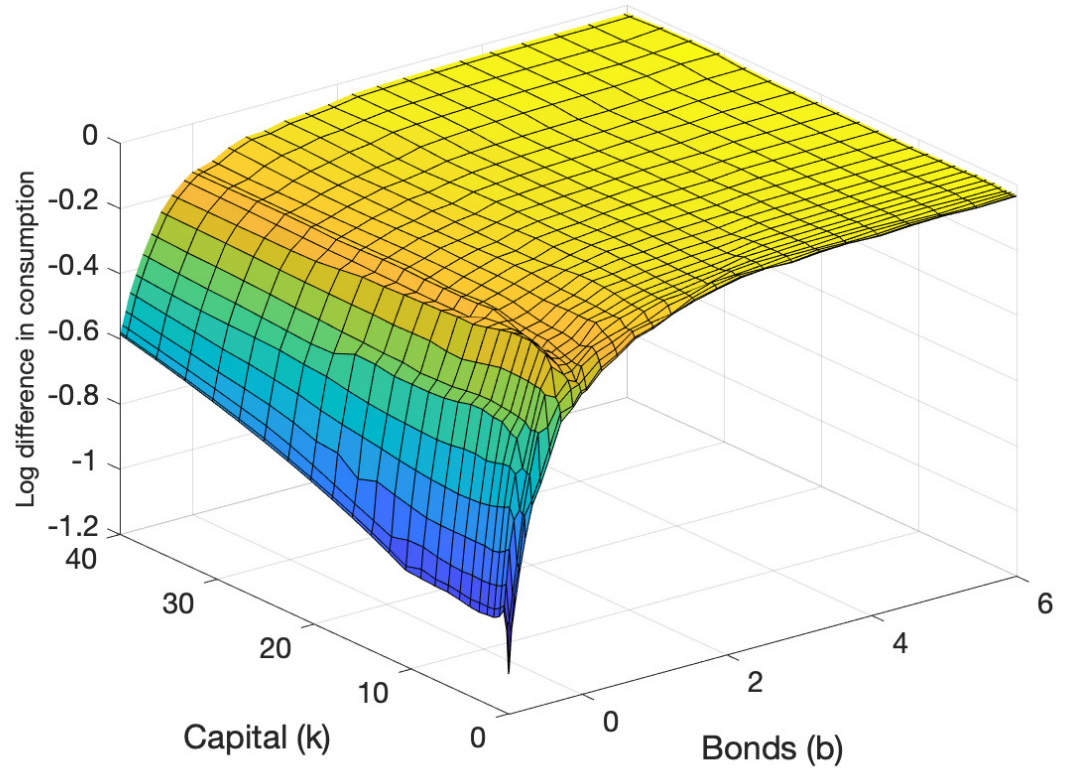

(a) Not Adjusting $k$

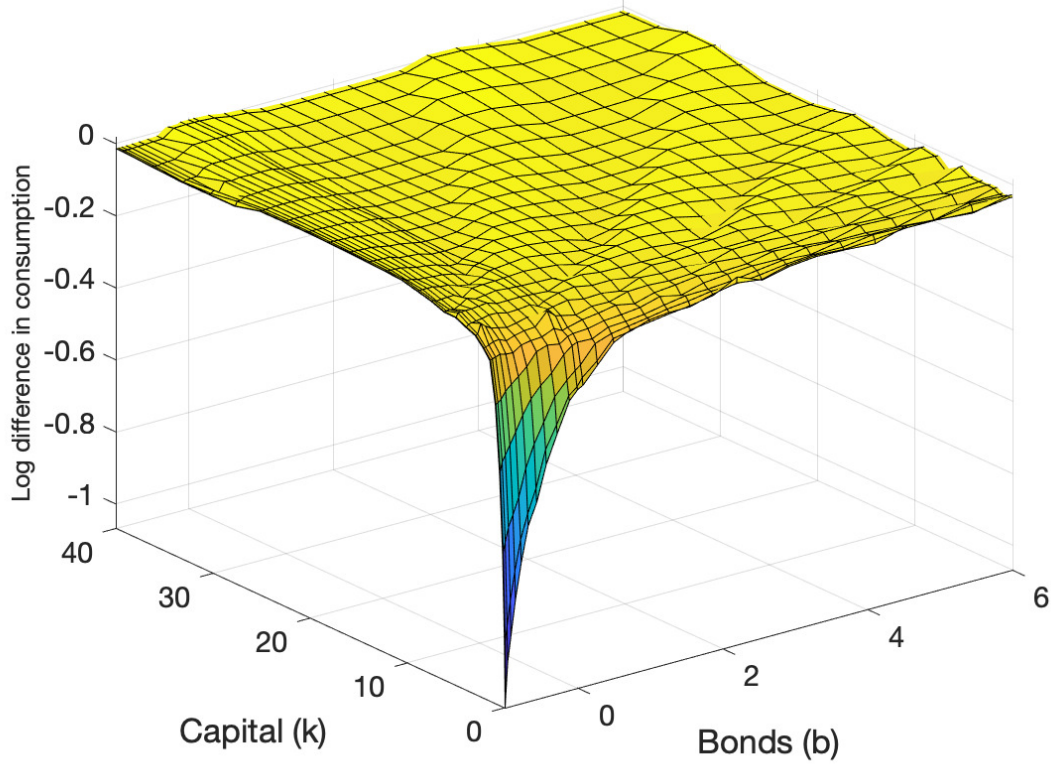

(b) Adjusting $k$

Notes: These figures plot the log difference in consumption between employed and unemployed households at the median level of productivity. The mean (median) value of $k$ in the steady-state of the model is 34 (6). The mean (median) value of $b$ is $3.3(0.5)$. 


\section{Table 6: Illiquid Asset Withdrawal Probabilities}

\begin{tabular}{lcc} 
& Probability & Model \\
\hline Full Sample & 0.045 & 0.119 \\
\hline No Unemployment Spell & 0.038 & 0.100 \\
Unemployment Spell & 0.106 & 0.212 \\
\hline Short Unemployment Spell & 0.062 & 0.162 \\
Long Unemployment Spell & 0.157 & 0.314 \\
\hline Unemployment Spell \& Non-HTM & 0.066 & 0.105 \\
Unemployment Spell \& HTM & 0.123 & 0.294 \\
\hline
\end{tabular}

Notes: Probabilities constructed using sampling weights from a sample of 4211 households from the 2004 to 2016 waves of the SCF. I define an unemployment spell as short if it is 12 weeks or less.

date capital during unemployment. Consequently, the average consumption decline for the wealthy hand-to-mouth is between that of the poor hand-to-mouth and the non hand-tomouth, as in the data.

\subsection{Illiquid Asset Response to Unemployment Spells}

Table 6 compares the illiquid asset withdrawal probabilities in the model and the data. As individual retirement accounts are only one type of illiquid asset, there is no direct comparability between the levels of the withdrawal probabilities in the model and the data. ${ }^{20}$ The true withdrawal probabilities in the data are higher when including withdrawals from other illiquid assets, such as housing. ${ }^{21}$ However, it is possible to validate the model by considering the relative effect of unemployment and liquid asset holdings on withdrawal probabilities.

The model matches the patterns seen in the data. In both the model and the data the withdrawal probability for households who experienced an unemployment spell is more than twice that of households who did not. The model also matches the finding in the data that withdrawal probabilities are significantly higher if the unemployment spell lasted longer

\footnotetext{
${ }^{20} \mathrm{Also}$, household decisions regarding retirement accounts are intimately tied up with life-cycle considerations, from which the model abstracts.

${ }^{21}$ Neil Bhutta and Benjamin J Keys (2016) find that an average of $11 \%$ of households extracted equity from their home each year between 1999 and 2010.
} 
than one quarter and if the unemployment spell occurred when the household had few liquid assets.

Figures $4 \mathrm{a}$ and 4b plot illiquid asset adjustment probabilities across the liquid and illiquid wealth distributions for employed and unemployed households to highlight the importance of employment status for illiquid asset adjustment in the model. ${ }^{22}$ In both cases, adjustment probabilities are highest when households hold unbalanced portfolios: households with high illiquid asset holdings but low liquid asset holdings would like to shift their portfolio towards liquid assets, while households with low illiquid asset holdings and high liquid asset holdings would like to shift their portfolios in the opposite direction.

Comparing the two figures shows how employment status affects adjustment probabilities. Relative to employed households, unemployed households are much more likely to withdraw from their illiquid asset holdings when their liquid asset holdings are low. Figure 3 showed that such households can only smooth their consumption during unemployment if they liquidate their illiquid asset holdings. Unemployed households are also less likely to increase their illiquid asset holdings when their liquid asset holdings are high, as they are aware that they may need to use their their liquid assets to smooth consumption if the unemployment spell is persistent.

\section{Response of the Economy to Aggregate Shocks}

In this section, I consider the response of the economy to an unanticipated negative shock to aggregate productivity. ${ }^{23}$ To understand whether or not unemployment risk affects business cycle dynamics, and if unemployment insurance is an important automatic stabilizer, I compare the impulse responses of three different versions of the model: the baseline model, a model with no unemployment insurance, and a model with no unemployment insurance but in which households pool their idiosyncratic unemployment risk perfectly. ${ }^{24}$

\footnotetext{
${ }^{22}$ As in Figure 3, this is shown at the median level of productivity.

${ }^{23}$ I consider a shock which lowers aggregate productivity by $0.13 \%$ on impact, and has a quarterly persistence equal to 0.9 .

${ }^{24}$ In these alternate versions of the model, I adjust $\bar{w}$ so that the unemployment rate remains at $6 \%$ in the steady-state. I also assume that the steady-state real interest rate remains at $1 \%$ in each version of the model. In response to the aggregate shock, I assume that government spending adjusts to balance the government's budget constraint each period. Kaplan, Moll and Violante (2018) discuss the importance of assumptions regarding fiscal policy in HANK economies.
} 


\section{Figure 4: Adjustment Probabilities and Employment Status}

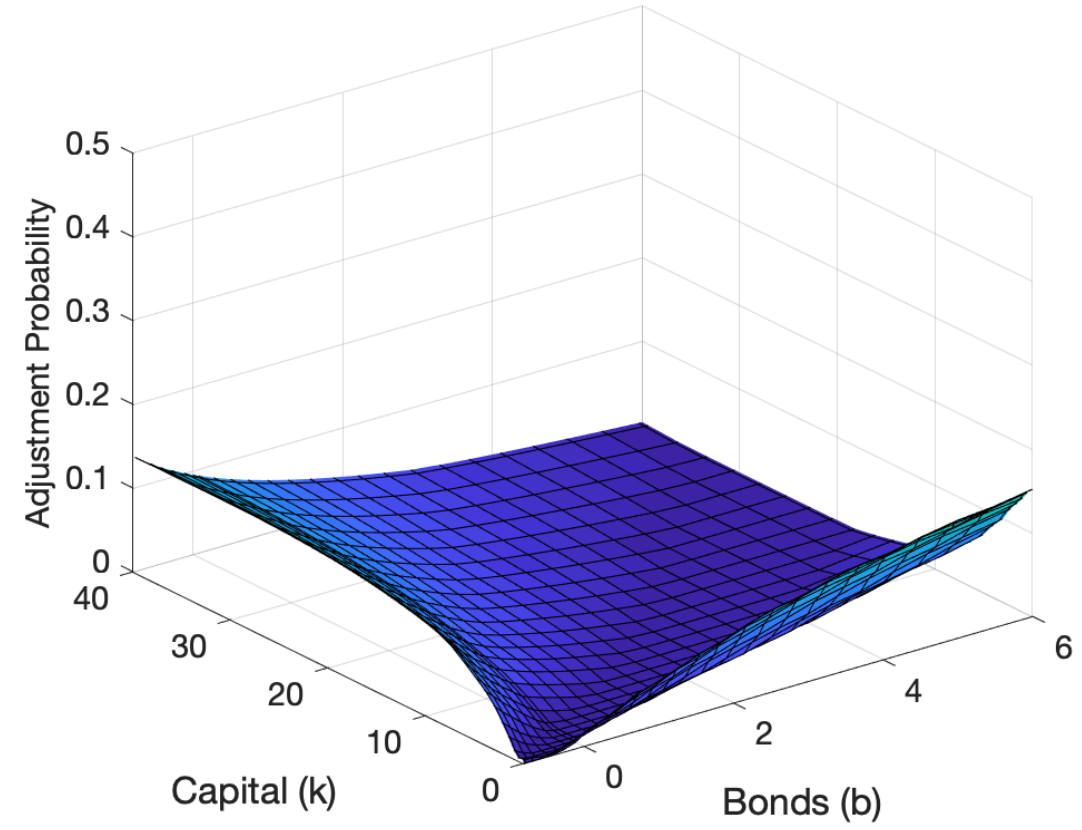

(a) Employed

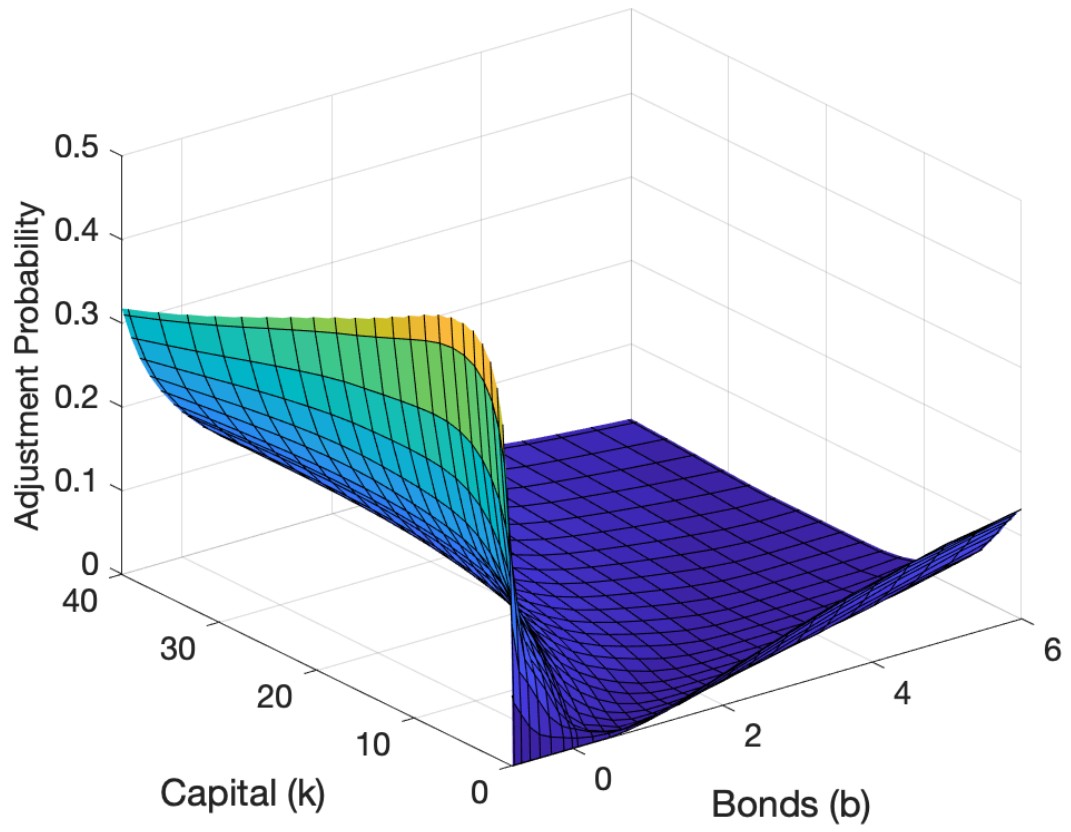

(b) Unemployed

Notes: The mean (median) value of $k$ in the steady-state of the model is $34(6)$. The mean (median) value of $b$ is $3.3(0.5)$. 
By comparing the second and third versions of the model, I am able to assess the importance of unemployment risk on aggregate fluctuations. The baseline model then shows the degree to which unemployment insurance is able to mitigate any amplification due to idiosyncratic unemployment risk. Figure 5 plots the impulse response of key variables to the aggregate productivity shock in each version of the model.

In all versions of the model, the decline in aggregate productivity causes a decline in vacancy posting and a rise in the unemployment rate. In response to an increase in unemployment risk, there is a flight-to-liquidity: demand for liquid assets increases, as these are best-suited to smoothing consumption during unemployment spells. Investment in capital falls, as employed households postpone investing in illiquid assets, and unemployed households withdraw from their illiquid asset holdings. In the presence of nominal rigidities, this decline in investment demand lowers aggregate output, raises unemployment, and initiates a feedback loop between unemployment risk and aggregate demand in the economy.

This mechanism is not operative if unemployment risk is pooled, and it is dampened if households have access to unemployment insurance. By providing a source of income during unemployment spells, unemployment insurance lessens the need for holding liquid assets to smooth consumption during such times.

The quantitative significance of this mechanism can be seen in Figure 5. The main result is that the unemployment rate rises by around 35\% more in the version without unemployment insurance than in the version with no unemployment risk, and that unemployment insurance removes around half of this amplification. The more unemployment risk that households face, the larger is the decline in investment, and the sharper is the decline in the real interest rate. The bottom-right panel of Figure 5 plots the liquidity premium, the spread between the rate of return on capital and the real interest rate. In all versions of the model, the spread is counter-cyclical, but this effect is stronger the more unemployment risk households face.

In the above experiment, I assume that government spending adjusts to balance the government's budget constraint each period. In Appendix G.5, I instead assume that the lumpsum transfer, $T_{t}$, adjusts. In this case, the amplification from unemployment risk remains. However, unemployment insurance is now somewhat effective in reducing this amplification. When government spending adjusts, the provision of unemployment insurance supports total household income when unemployment increases. When the lump-sum transfer adjusts, 
Figure 5: Response to an Aggregate Productivity Shock
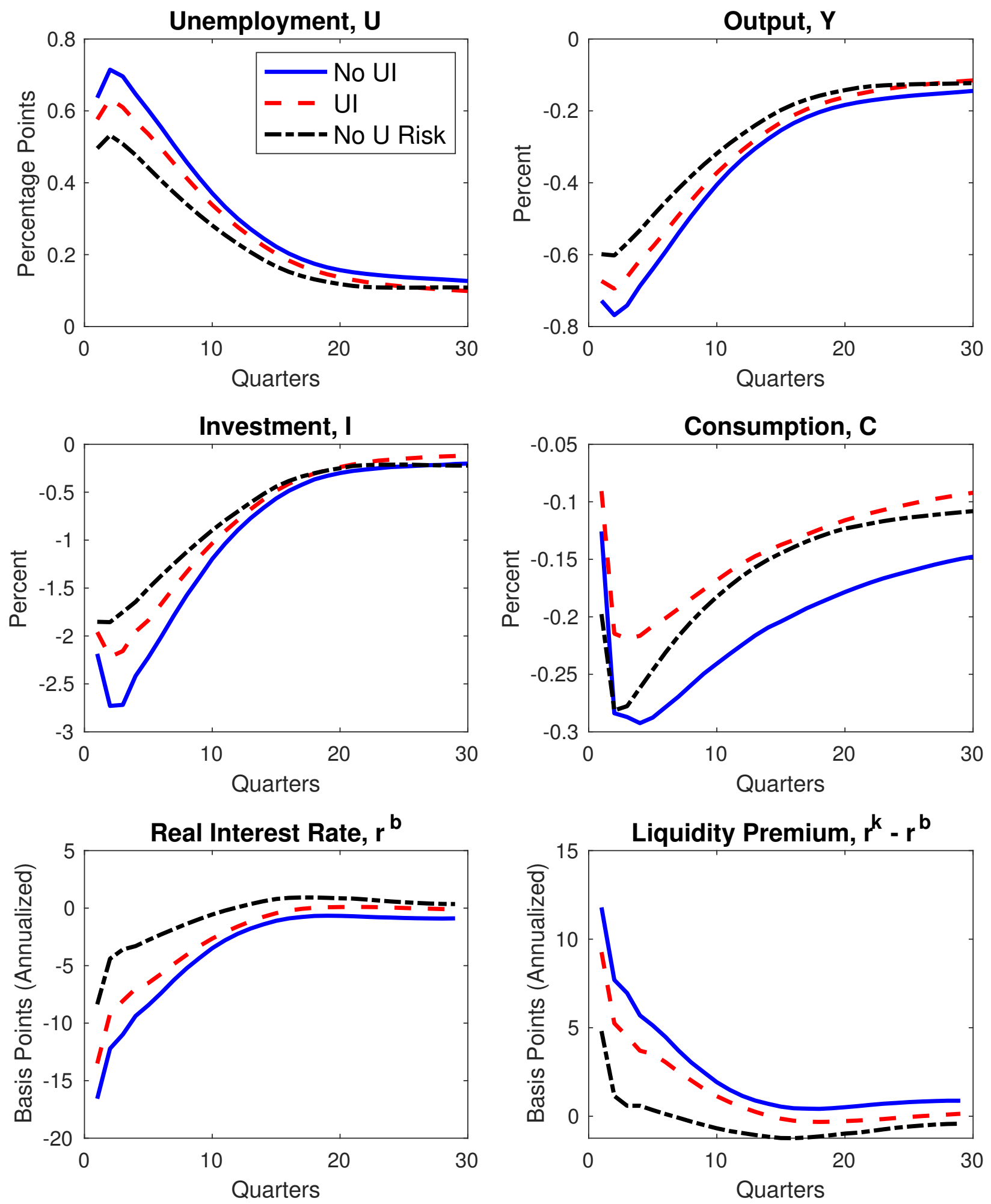
unemployment insurance redistributes from the employed to the unemployed, but does not provide any support to total household income.

\subsection{The Endogenous Response of Income Risk}

In this section, I show that the endogenous response of income risk to the aggregate shock in the model is consistent with empirical evidence from the CPS. Guvenen, Ozkan and Song (2014) use Social Security Administration data to show that the skewness of the income growth distribution is strongly pro-cyclical: recessions are times when large negative income changes become much more likely. Using data from the March supplement of the CPS, I am able to break down income growth into hours growth and wage growth. Figure 6 shows that the pro-cyclical skewness of income growth is entirely driven by the pro-cyclical skewness of hours growth, while the distribution of hourly wage growth doesn't vary over the business cycle. Thus, large negative income changes in recessions become more likely due to an increased likelihood of a large decline in hours worked, i.e. an unemployment spell. In Appendix E I provide more detail on the CPS data and additional evidence that the cyclicality of income growth is driven by the cyclicality of unemployment risk.

Figure 7 shows the effect of the aggregate shock on the skewness of the hours growth, wage growth and income growth distributions in the model. As in the data, the skewness of income growth is pro-cyclical, and it is driven entirely by the skewness of hours growth, which responds by around twice as much as the skewness of income growth. In the model, the skewness of the wage growth distribution is acyclical by construction, as it depends only on the stochastic process for idiosyncratic productivity.

Figure 7 is also useful for understanding why the flight-to-liquidity mechanism is not operative in the version of the model where unemployment risk is pooled. In this version of the model, the only source of income risk comes from idiosyncratic productivity shocks, so the skewness of the income growth distribution is unaffected by changes in the unemployment rate. 
Figure 6: Breakdown of Income Growth Skewness

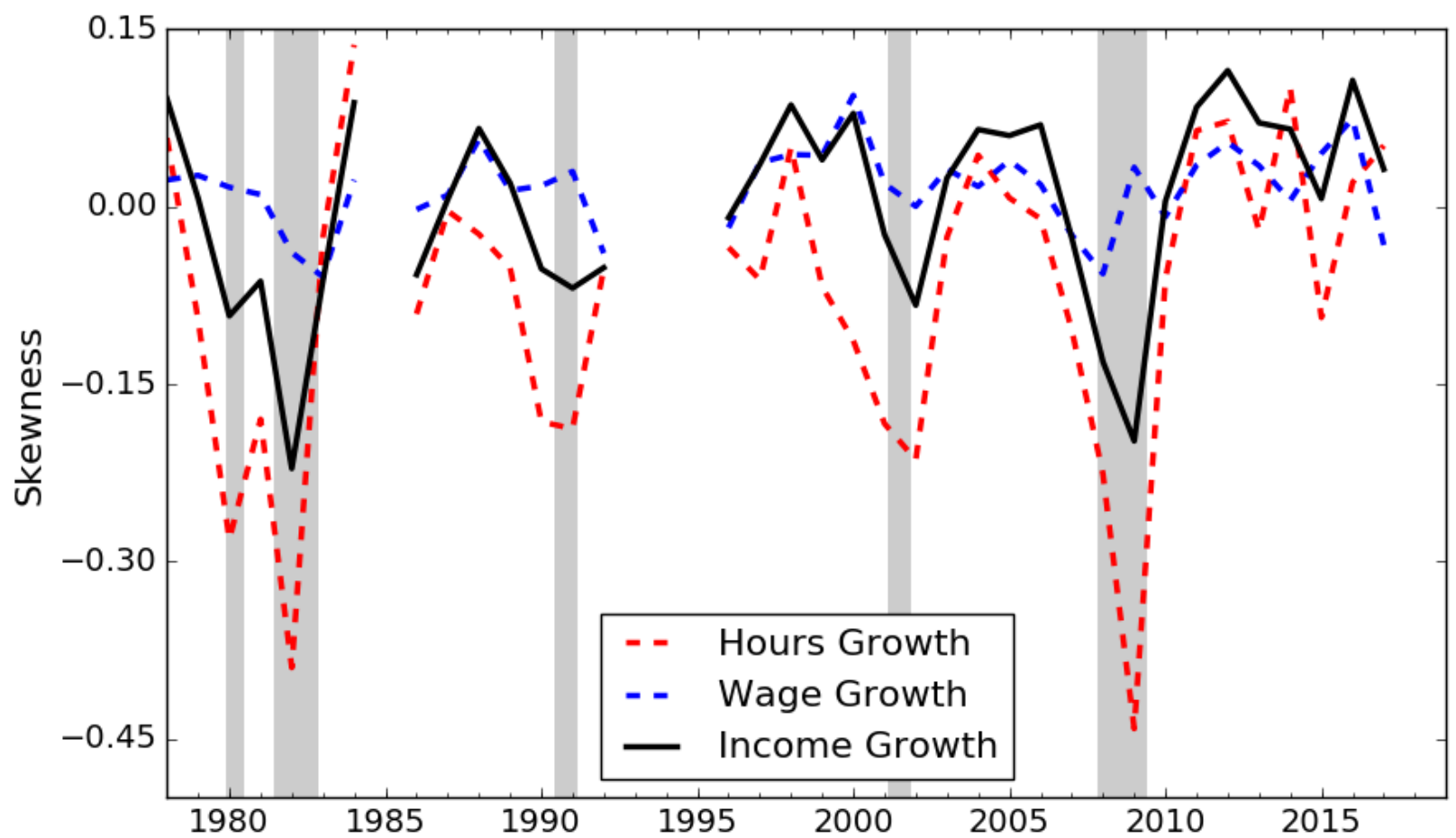

Notes: Data from the Current Population Survey. Skewness measured using Pearson's second skewness coefficient (median skewness).

Figure 7: Model Response of Income Risk
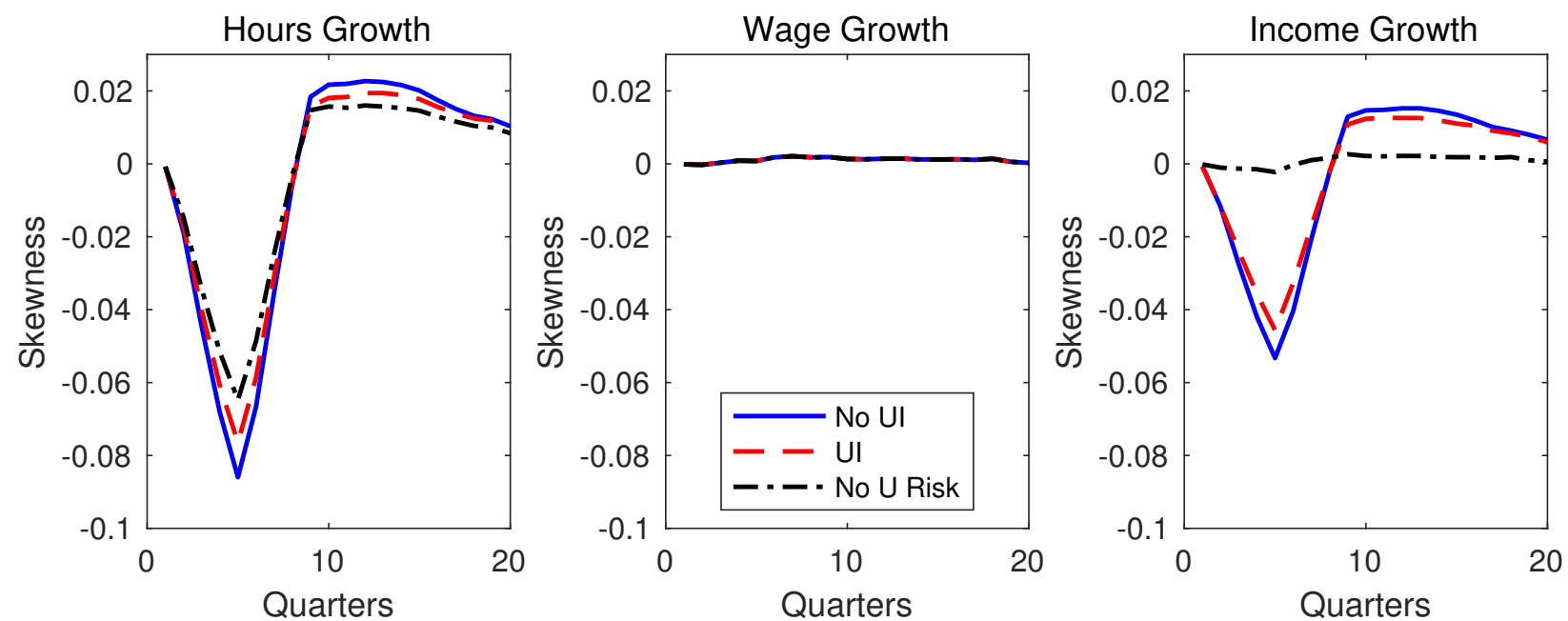

Notes: Skewness measured using Pearson's second skewness coefficient (median skewness). 


\subsection{The Importance of Unemployment Insurance at the ZLB}

I now consider how the importance of unemployment insurance as an automatic stabilizer depends on the responsiveness of monetary policy. I consider the response of the economy to the same aggregate productivity shock considered previously. However, I now assume that there is an exogenous lower bound on the nominal interest rate, such that monetary policy follows a truncated Taylor rule:

$$
i_{t}=\max \left\{\bar{r}^{b}+\psi \log \left(\Pi_{t}\right), \underline{\mathrm{i}}\right\}
$$

I set $\underline{i}$ such that monetary policy is constrained for 3 quarters in the baseline version of the model. ${ }^{25}$ Figure 8 compares the impulse response functions of the baseline model with those from the versions of the model without unemployment insurance or without unemployment risk.

When monetary policy is constrained, the decline in investment demand that follows the increase in unemployment risk is not offset by lower interest rates. This strengthens the feedback loop between aggregate demand and unemployment risk, and increases the amplification coming from the flight-to-liquidity mechanism. Unemployment insurance plays a much more important role than in normal times: without unemployment insurance, unemployment rises by almost $70 \%$ more than in the baseline model. Monetary policy is constrained for longer, and both investment and inflation decline by almost twice as much as they do with the baseline level of unemployment insurance.

The COVID-19 pandemic has pushed nominal interest rates back to the zero lower bound in almost all advanced economies. The message provided by this section is that unemployment insurance is particularly important as an automatic stabilizer at this time.

\footnotetext{
${ }^{25}$ The standard method for engineering a ZLB episode in New Keynesian models is a temporary rise in the discount factor, $\beta$. This does not work in this model due to the presence of capital and labor market frictions. Increasing the discount factor leads to a decline in unemployment, both because of an increase in the capital stock, which increases labor productivity, but also because a higher discount rate raises the value of a filled vacancy to the labor agency.
} 
Figure 8: Response to Shock with Constrained Monetary Policy
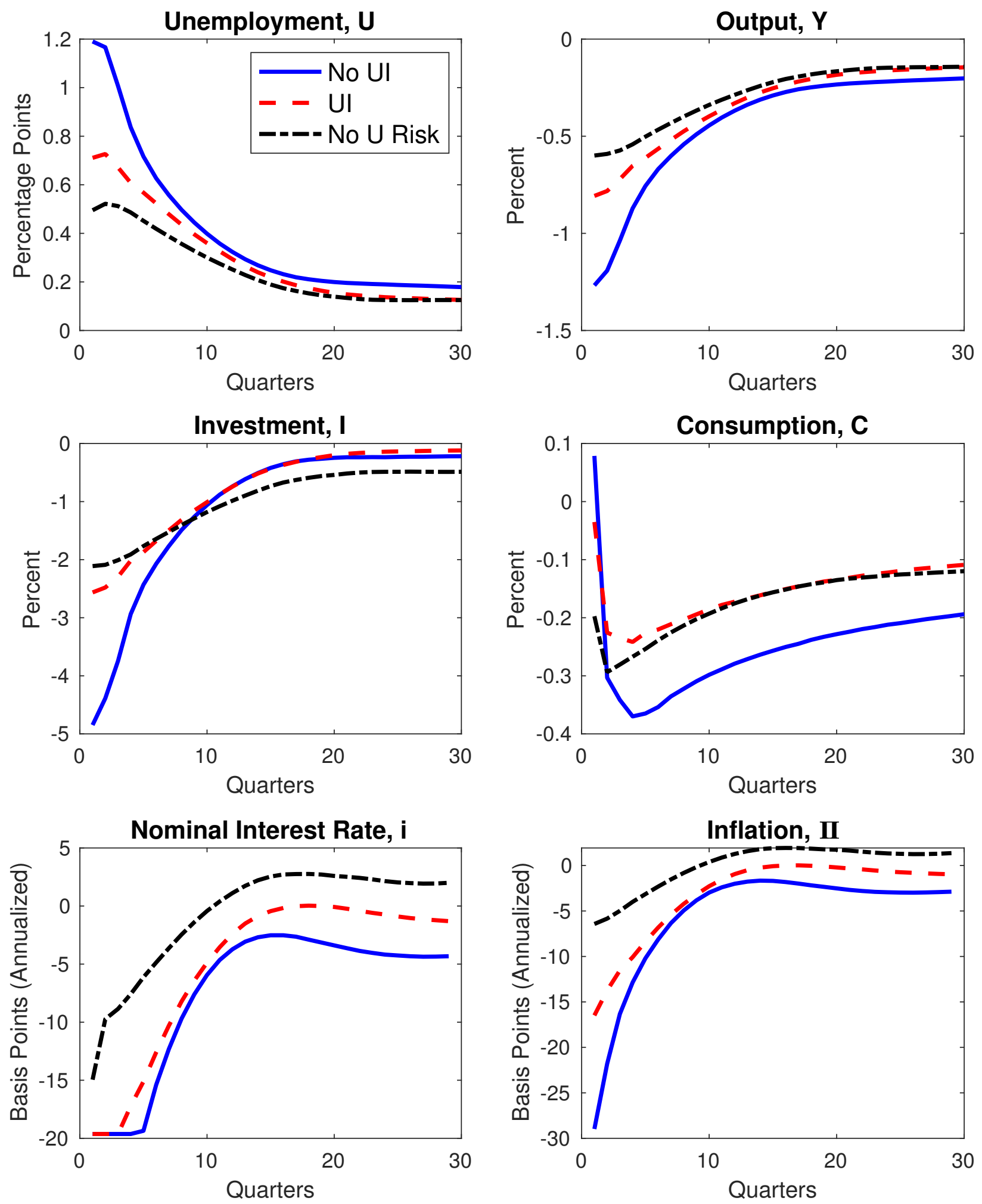


\section{Comparison with a One-Asset Model}

To understand the importance of the flight-to-liquidity mechanism for generating amplification, I now consider the response to the same aggregate productivity shock as in Section 6 in a model with only one asset, liquid bonds. Without illiquid capital the production function for the intermediate good producers is:

$$
y_{j, t}=A_{t} n_{j, t}
$$

Their marginal cost is equal to $m_{t}=\frac{h_{t}}{A_{t}}$. Given this, the New Keynesian Phillip's Curve is unchanged. The household's problem simplifies to:

$$
\begin{aligned}
V_{t}(b, z, e) & =\max _{c, b^{\prime}} \frac{c^{1-\gamma}}{1-\gamma}+\beta \mathbb{E}_{e^{\prime}, z^{\prime}} V_{t+1}\left(b^{\prime}, z^{\prime}, e^{\prime}\right) \\
& \text { subject to } \\
b^{\prime}+c & =\mathbb{1}\{e=1\} w_{t} z(1-\tau)+\mathbb{1}\{e=0\} w_{t} \phi(z)(1-\tau)+R_{t}^{b}(b) b+T_{t} \\
b^{\prime} & \geqslant \underline{\mathrm{b}} \\
z^{\prime} & =\Gamma(z)
\end{aligned}
$$

The rest of the model: the labor agency's problem and fiscal and monetary policies, are unchanged by the removal of capital. I leave the calibration as close to the two asset model as possible. ${ }^{26}$ Table 7 shows that the one-asset model slightly under-predicts median liquid asset holdings and slightly over-predicts the fraction of households that hold close to zero liquid assets. The one area where the calibration of the one-asset model fails significantly is the total liquid assets to output ratio: without an alternative saving vehicle wealthy households hold too many liquid assets, implying that total liquid asset holdings are too high.

Figure 9 plots the response of key variables to the aggregate productivity shock in all three versions of the model. The main result is that the path of the unemployment rate and aggregate output is almost identical in all three scenarios. Idiosyncratic unemployment risk does not affect business cycle dynamics in this model, and unemployment insurance plays no role as an automatic stabilizer.

\footnotetext{
${ }^{26} \mathrm{I}$ adjust the mean wage $\bar{w}$ to keep the unemployment rate at $6 \%$ in the steady state and then lower the values of the vacancy cost $c$, the transfer $T$, and the borrowing limit $\underline{\mathrm{b}}$ such that they remain the same relative to $\bar{w}$.
} 
Figure 9: Aggregate Productivity Shock (One-Asset Model)
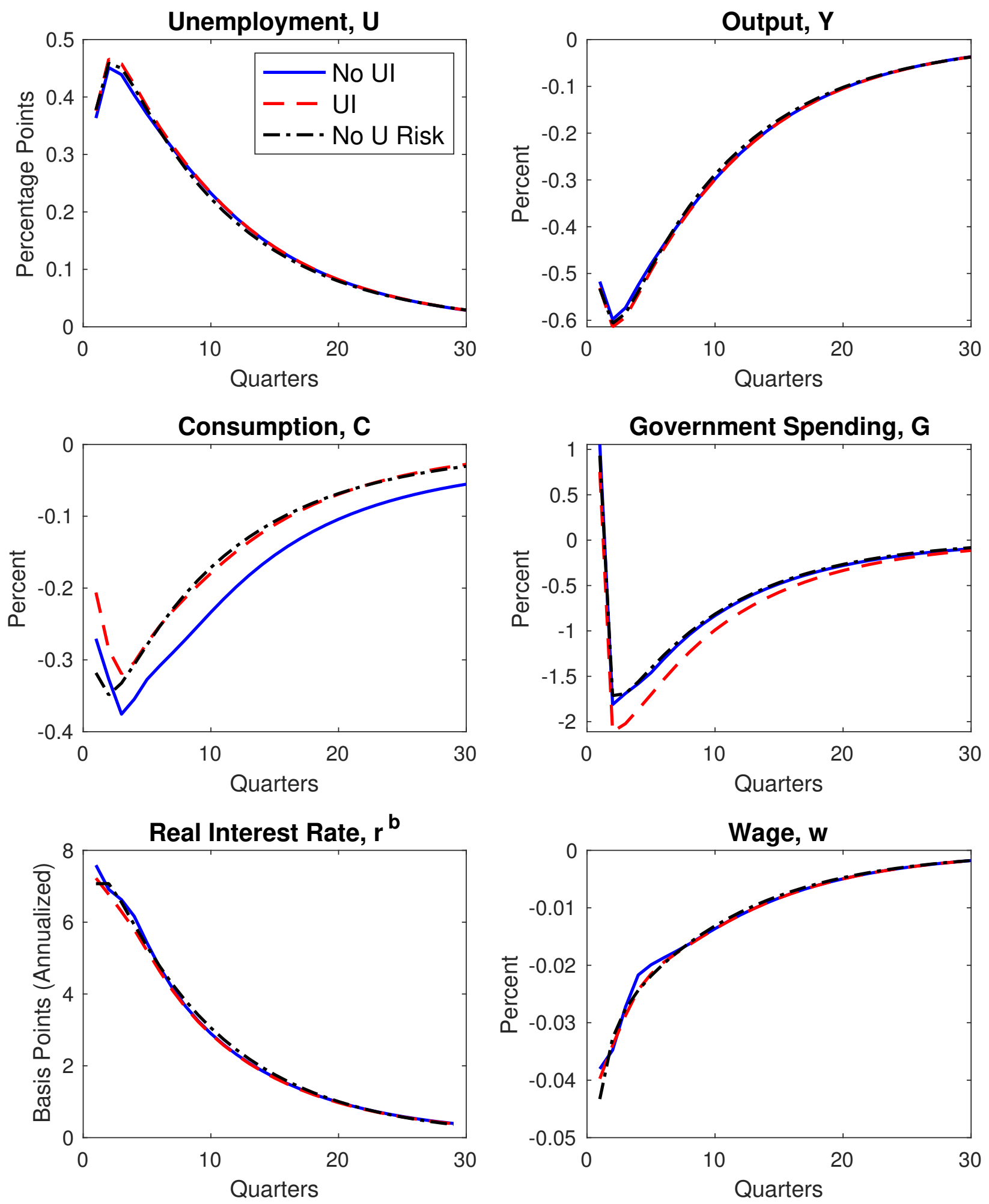


\section{Table 7: Liquid Wealth Distribution}

\begin{tabular}{lccc} 
Moment & Data & One-Asset Model & Two-Asset Model \\
\hline Median Liquid Assets/Average Income & 0.12 & -0.05 & 0.24 \\
\% Negative Liquid Assets & 0.15 & 0.14 & 0.16 \\
\% Hand-to-Mouth & 0.30 & 0.51 & 0.30 \\
Liquid Assets/Output & 0.26 & 2.31 & 0.27 \\
\hline
\end{tabular}

Notes: Median liquid asset holdings reported relative to average quarterly wage income.

Why does the one-asset model have such different predictions to the two-asset model? The key is in the path of the real interest rate. In the two-asset model, the version without unemployment insurance saw a substantially larger decline in the real interest rate, relative to the other two versions of the model. The one-asset model shows that the key driver of this difference was the flight-to-liquidity caused by higher unemployment risk: In the one-asset model, the interest rate path is almost identical in all three versions of the model.

Without the flight-to-liquidity mechanism, the only forces affecting the path of the real interest rate come from household's consumption/saving decisions. On the one hand, when the unemployment rate is elevated, employed households have a greater incentive to save, as they are more likely to become unemployed in the future. However, there is an opposing force coming from the consumption smoothing motive of unemployed households, who wish to borrow while their income is temporarily low. Figure 9 implies that these forces almost exactly offset each other, such that the path of the real interest rate is unaffected by the degree of unemployment risk or generosity of unemployment insurance. In a New Keynesian model such as this, equivalence of the path of the real interest rate translates into equivalence in the path of aggregate output and employment.

One obvious question is why these results are so different from those in Ravn and Sterk (2017). Their paper assesses the role of unemployment risk in a one-asset HANK model and finds large amplification. The key difference is the assumption that they make about the liquid asset distribution. In particular, they assume that agents hold no assets in equilibrium. The path of the real interest rate is determined by employed households, whose Euler equation holds with equality, while unemployed households are borrowing constrained. These assumptions imply that the only force affecting the path of the real interest rate in their economy is the consumption smoothing motive of the employed households, as unemployed households are unable to borrow. 
Figure 10: Varying $\beta$ in the One-Asset Model
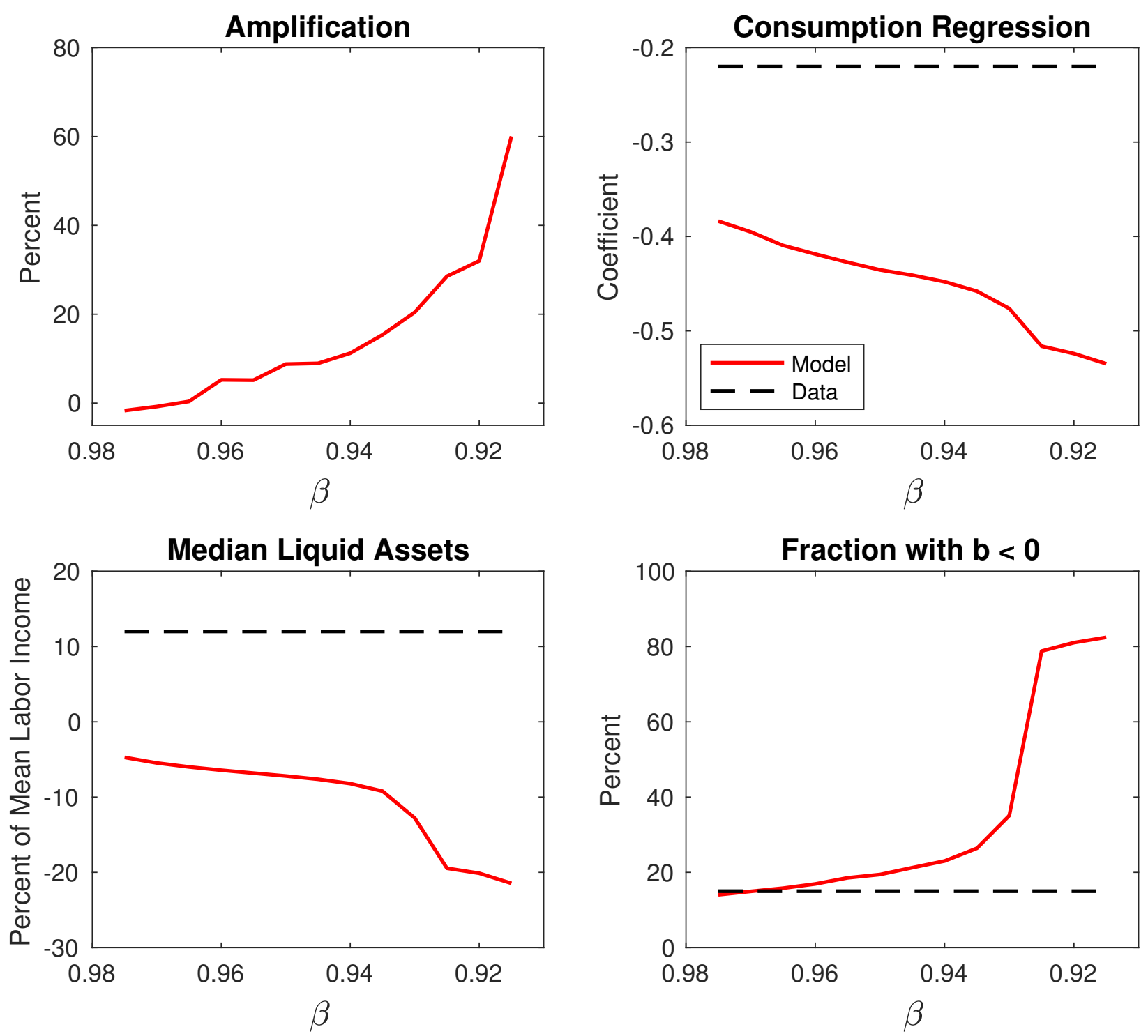

Notes: Amplification measured as the maximum change in unemployment in the version of the model with no unemployment insurance relative to the maximum change in the version of the model with no unemployment risk.

In Figure 10, I show the effect of gradually lowering $\beta$ in the one-asset model from 0.975 to 0.905 . When $\beta$ is close to 0.905 , the model does display significant amplification, as in Ravn and Sterk (2017). However, in such a calibration almost all households are borrowing constrained: median liquid asset holdings are far too low, too many households have negative liquid asset holdings, and the consumption decline during unemployment is much larger than in the data. 


\section{Conclusion}

This paper shows that the combination of endogenous unemployment risk and the presence of illiquid assets provides a novel propagation mechanism for aggregate shocks: higher unemployment risk leads to a flight-to-liquidity and initiates a feedback loop between unemployment risk and aggregate demand. Unemployment insurance plays an important role as an automatic stabilizer, particularly if monetary policy is constrained. The presence of both liquid and illiquid assets is key: if households have access to only one asset, and that asset is liquid, unemployment risk does not endogenously affect business cycle dynamics.

The two-asset model is also consistent with new empirical evidence on the relationship between unemployment and the liquidity of asset holdings. Using data from the Consumer Expenditure Survey, I find that the consumption decline during unemployment is largest for poor hand-to-mouth households, smaller for the wealthy hand-to-mouth, and smallest for the non hand-to-mouth. The two-asset model is able to match this finding due to the costs associated with adjusting illiquid asset holdings. Some wealthy hand-to-mouth households pay these adjustment costs, and consequently are able to smooth their consumption as well as the non hand-to-mouth, while others do not pay the adjustment costs and are unable to smooth their consumption, like poor hand-to-mouth households.

In the model, unemployed households do not need to withdraw from their illiquid asset holdings until they have first run down their liquid asset holdings. However, when their liquid asset holdings are depleted, they are then likely to withdraw from their illiquid asset holdings. Consequently, unemployed households are more likely to make a withdrawal from their illiquid asset holdings than employed households, particularly if their unemployment spell is long or their liquid asset holdings are low. Using data from the Survey of Consumer Finances I show that these patterns are confirmed in the data.

The model suggests that an important role for unemployment insurance is its ability to dampen aggregate fluctuations by lessening the flight-to-liquidity that occurs when unemployment risk is heightened. However, the model has abstracted from search effort on the part of unemployed workers, or any mechanism by which unemployment insurance affects the level of wages. Consequently, there is likely an important trade-off between the effect of

unemployment insurance on the volatility of the unemployment rate and the effect on the average level of unemployment. I leave an investigation of this trade-off to future work. 


\section{References}

Acharya, Sushant, and Keshav Dogra. 2018. "Understanding HANK: Insights from a PRANK." FRB of New York Staff Report, , (835).

Aguiar, Mark, and Erik Hurst. 2005. "Consumption versus Expenditure." Journal of Political Economy, 113(5): 919-948.

Aiyagari, S. Rao, and Mark Gertler. 1991. "Asset returns with transactions costs and uninsured individual risk." Journal of Monetary Economics, 27(3): 311-331.

Auclert, Adrien, Matthew Rognlie, and Ludwig Straub. 2018. "The Intertemporal Keynesian Cross." National Bureau of Economic Research, Inc NBER Working Papers 25020.

Bayer, Christian, Ralph Lütticke, Lien Pham-Dao, and Volker Tjaden. 2019. "Precautionary savings, illiquid assets, and the aggregate consequences of shocks to household income risk." Econometrica, 87(1): 255-290.

Bhutta, Neil, and Benjamin J Keys. 2016. "Interest rates and equity extraction during the housing boom." American Economic Review, 106(7): 1742-74.

Birinci, Serdar, and Kurt Gerrard See. 2018. "How Should Unemployment Insurance vary over the Business Cycle?"

Bloom, Nicholas. 2009. "The Impact of Uncertainty Shocks." Econometrica, 77(3): 623685.

Boppart, Timo, Per Krusell, and Kurt Mitman. 2018. "Exploiting MIT shocks in heterogeneous-agent economies: the impulse response as a numerical derivative." Journal of Economic Dynamics and Control, 89: 68-92.

Braxton, J. Carter, Gordon Phillips, and Kyle Herkenhoff. 2018. "Can the Unemployed Borrow? Implications for Public Insurance." Society for Economic Dynamics 2018 Meeting Papers 564.

Browning, Martin, and Thomas F Crossley. 2001. "Unemployment insurance benefit levels and consumption changes." Journal of public Economics, 80(1): 1-23.

Busch, Christopher, David Domeij, Fatih Guvenen, and Rocio Madera. 2018. 
"Asymmetric Business-Cycle Risk and Social Insurance." National Bureau of Economic Research.

Challe, Edouard, and Xavier Ragot. 2015. "Precautionary saving over the business cycle." The Economic Journal, 126(590): 135-164.

Challe, Edouard, Julien Matheron, Xavier Ragot, and Juan F Rubio-Ramirez. 2017. "Precautionary saving and aggregate demand." Quantitative Economics, 8(2): 435478.

Cho, Daeha. 2018. "Unemployment Risk and Business Cycles."

Chodorow-Reich, Gabriel, and Loukas Karabarbounis. 2016. "The cyclicality of the opportunity cost of employment." Journal of Political Economy, 124(6): 1563-1618.

Christiano, Lawrence J, Martin S Eichenbaum, and Mathias Trabandt. 2016a. "Unemployment and business cycles." Econometrica, 84(4): 1523-1569.

Christiano, Lawrence J, Martin S Eichenbaum, and Mathias Trabandt. $2016 b$. "Unemployment and Business Cycles." Econometrica, 84(4): 1523-1569.

Coibion, Olivier, Yuriy Gorodnichenko, Lorenz Kueng, and John Silvia. 2017. "Innocent Bystanders? Monetary policy and inequality." Journal of Monetary Economics, 88: 70-89.

Davis, Steven J., and Till Von Wachter. 2011. "Recessions and the Costs of Job Loss." Brookings Papers on Economic Activity, 42(2 (Fall)): 1-72.

Den Haan, Wouter J, Garey Ramey, and Joel Watson. 2000. "Job destruction and propagation of shocks." American economic review, 90(3): 482-498.

Den Haan, Wouter J, Pontus Rendahl, and Markus Riegler. 2017. "Unemployment (fears) and deflationary spirals." Journal of the European Economic Association, 16(5): 1281-1349.

Department of Labor. 2018. "Comparison of State Unemployment Laws."

Faccini, Renato, and Pontus Rendahl. 2019. "Income Risk, Asset Prices, and Labor Market Cyclicality." 
Ganong, Peter, and Pascal Noel. 2019. "Consumer spending during unemployment: Positive and normative implications." American Economic Review, 109(7): 2383-2424.

Gilchrist, Simon, and Egon Zakrajšek. 2012. "Credit spreads and business cycle fluctuations." American Economic Review, 102(4): 1692-1720.

Gornemann, Nils, Keith Kuester, and Makoto Nakajima. 2016. "Doves for the rich, hawks for the poor? Distributional consequences of monetary policy."

Greenwood, Jeremy, Zvi Hercowitz, and Gregory W Huffman. 1988. "Investment, capacity utilization, and the real business cycle." The American Economic Review, 402417.

Gruber, Jonathan. 1997. "The Consumption Smoothing Benefits of Unemployment Insurance." The American Economic Review, 87(1): 192-205.

Guvenen, Fatih, Fatih Karahan, Serdar Ozkan, and Jae Song. 2015. "What do data on millions of US workers reveal about life-cycle earnings risk?" National Bureau of Economic Research.

Guvenen, Fatih, Serdar Ozkan, and Jae Song. 2014. "The nature of countercyclical income risk." Journal of Political Economy, 122(3): 621-660.

Hagedorn, Marcus, and Iourii Manovskii. 2008. "The cyclical behavior of equilibrium unemployment and vacancies revisited." American Economic Review, 98(4): 1692-1706.

Hoffmann, Eran B., and Davide Malacrino. 2019. "Employment time and the cyclicality of earnings growth." Journal of Public Economics, 169(C): 160-171.

Johnson, David S, Jonathan A Parker, and Nicholas S Souleles. 2006. "Household expenditure and the income tax rebates of 2001." American Economic Review, 96(5): 15891610.

Jordà, Òscar. 2005. "Estimation and inference of impulse responses by local projections." American economic review, 95(1): 161-182.

Kaplan, Greg, and Giovanni L Violante. 2014. "A model of the consumption response to fiscal stimulus payments." Econometrica, 82(4): 1199-1239.

Kaplan, Greg, Benjamin Moll, and Giovanni L Violante. 2018. "Monetary policy 
according to HANK." American Economic Review, 108(3): 697-743.

Kaplan, Greg, Giovanni L. Violante, and Justin Weidner. 2014. "The Wealthy Handto-Mouth." Brookings Papers on Economic Activity, 45(1 (Spring)): 77-153.

Kaplan, Greg, Kurt Mitman, and Giovanni L Violante. 2017. "The housing boom and bust: Model meets evidence." National Bureau of Economic Research.

Kekre, Rohan. 2016. "Unemployment Insurance in Macroeconomic Stabilization."

Kolsrud, Jonas, Camille Landais, Peter Nilsson, and Johannes Spinnewijn. 2018. "The optimal timing of unemployment benefits: Theory and evidence from sweden." American Economic Review, 108(4-5): 985-1033.

Krueger, D., K. Mitman, and F. Perri. 2016. "Macroeconomics and Household Heterogeneity." Vol. 2 of Handbook of Macroeconomics, Chapter 0, 843-921. Elsevier.

Maggio, Marco Di, and Amir Kermani. 2016. "The Importance of Unemployment Insurance as an Automatic Stabilizer." National Bureau of Economic Research.

McKay, Alisdair, and Ricardo Reis. 2016a. "Optimal automatic stabilizers." National Bureau of Economic Research.

McKay, Alisdair, and Ricardo Reis. 2016b. "The role of automatic stabilizers in the US business cycle." Econometrica, 84(1): 141-194.

Ravn, Morten O., and Vincent Sterk. 2017. "Job uncertainty and deep recessions." Journal of Monetary Economics, 90(C): 125-141.

Romer, Christina D, and David H Romer. 2004. "A new measure of monetary shocks: Derivation and implications." American Economic Review, 94(4): 1055-1084.

Rotemberg, Julio J. 1982. "Sticky prices in the United States." Journal of Political Economy, 90(6): 1187-1211.

Werning, Iván. 2015. "Incomplete markets and aggregate demand." National Bureau of Economic Research. 


\section{Appendices}

\section{A Data Sources}

\section{A.1 Consumer Expenditure Survey (CEX)}

I have constructed the CEX sample using the micro-data files provided by the BLS.

Following the previous literature on the relationship between household consumption and unemployment, I restrict attention to the consumption of non-durables and services. From total expenditure, I exclude spending on housing, health care, education, cash contributions, personal insurance, and automobiles. This is close to the definition of non-durables and services used by Chodorow-Reich and Karabarbounis (2016).

I select households whose head is between the ages of 25 and 55. As in Chodorow-Reich and Karabarbounis (2016), I drop households whose head or spouse work in farming, forestry, or the armed services.

The measurement of liquid asset holdings has changed over time in the CEX. For the most recent years, I use the variable LIQUDYRX, which measures the value of checking, savings, and money market accounts, as well as CDs, one year ago. Before 2013 this variable was not available, and I construct a similar measure using CKBKACTX (which measures the current value of checking accounts, brokerage accounts, and other similar accounts) and COMPCKG which measures the change in checking account balances over the previous year. In all years, I define households as hand-to-mouth if their liquid asset holdings are below the median value in that given year.

The CEX contains little information on a household's illiquid asset holdings. Consequently, I use housing tenure as a proxy for illiquid asset holdings. I define households as wealthy (poor) hand-to-mouth if they are hand-to-mouth by the above definition and they are homeowners (renters).

I measure employment at the household level using the number of weeks worked by the household head or spouse. I classify individuals who do not work during the year as unemployed if they report having looked for a job and out of the labor force if not. For individuals who 
worked for less than 52 weeks, I measure the fraction of the year that they were unemployed as 1 - weeks worked/52.

The following variables are included in the vector of controls: region/year fixed effects, race of the household head, age and age squared of the household head, family size and family size squared, education of the household head, housing tenure, number of cars, rental value of the home (split into deciles by region and year), hand-to-mouth status, and the fraction of the year spent out of the labor force.

\section{A.2 Panel Study of Income Dynamics (PSID)}

A broad measure of consumption expenditures is only available in the PSID from 2005 onwards. Consequently, I use data from the surveys between 2005 and 2017. As in the CEX, I restrict the sample to households whose head is between the ages of 25 and 55 .

The measure of liquid asset holdings that I use in the PSID is the value of checking or savings accounts, money market funds, certificates of deposit, government savings bonds, or Treasury bills. The measure of illiquid asset holdings is the value of housing equity and retirement accounts. Finally, the measure of consumption is food, clothing, recreation and vacation expenditures.

\section{A.3 Survey of Consumer Finances (SCF)}

I use micro-data from the SCF for the following survey years: 2004, 2007, 2010, 2013, and 2016. 2004 was the first year that the survey asked about withdrawals from individual retirement accounts.

The SCF uses a multiple imputation approach, given the low response rate to certain questions in the survey. To avoid any problems that could be introduced by this imputation, I restrict the sample to households who have no imputed data on the age of the household head, their weeks of unemployment in the previous 12 months, their ownership of any individual retirement accounts (IRAs), and the presence of any withdrawals from their IRA in the past year.

Generally, withdrawals from retirement accounts that occur before the age of 59.5 are subject 
to a $10 \%$ tax penalty. Consequently, I restrict the sample to households whose head is at most 55 years of age, consistent with the sample I use for the CEX in Section 2. I further restrict the sample to households where the household head reports having an IRA. This leaves 4211 households across the 5 survey waves. Overall, $24 \%$ of households in the SCF report ownership of an IRA.

Measurement of liquid asset holdings in the SCF requires a trade-off. On the one-hand, the survey contains questions on a relatively large number of assets that could be considered liquid. On the other hand, given my decision to not use imputed data, the larger the set of assets included, the smaller will be my final sample size. Consequently, I measure liquid asset holdings using only checking account balances. Even with this relatively crude measure, the sample size declines to 3153 households once I have removed households for whom checking account data is imputed.

\section{A.4 Current Population Survey (CPS)}

In Section 6.1 and Appendix E, I document the central role of unemployment risk in explaining cyclical changes in the income growth distribution. This is based on micro-data from the March supplement of the IPUMS CPS dataset between 1976 and 2018. Following Guvenen, Ozkan and Song (2014), I restrict the sample to men between the ages of 25 and 60, and I drop individuals who report either no weeks of work or no income in a particular year. The remaining sample size fluctuates between around 5000 and 9000 individuals per year.

I measure annual income using the IPUMS variable INCWAGE, which measures wage and salary income. I measure annual hours worked using the product of WKSWORK1, which measures the number of weeks worked during the year, and UHRSWORKLY, which measures the usual number of hours worked per week.

In Appendix E.1, I require a higher frequency measure of hours growth and wage growth, which requires using the monthly CPS sample. To construct a measure of wage growth, I use the NBER dataset on the Merged Outgoing Rotation Group (MORG), as individuals are

only asked about their earnings in their fourth and eights CPS interviews. For individuals in their last interview, I measure hourly wages as EARNWKE/UHOURSE.

To construct a measure of hours growth, I use the AHRSWORKT variable from the IPUMS data, which measures hours worked in the previous week (equal to 0 if the individual was 


\section{Table 8: Descriptive Statistics Across Asset Groups}

\begin{tabular}{|c|c|c|c|c|c|c|c|c|}
\hline & \multicolumn{2}{|c|}{ Full Sample } & \multicolumn{2}{|c|}{ N-HTM } & \multicolumn{2}{|c|}{ W-HTM } & \multicolumn{2}{|c|}{ P-HTM } \\
\hline & CEX & $\mathrm{SCF}$ & $\overline{\text { CEX }}$ & $\mathrm{SCF}$ & CEX & $\mathrm{SCF}$ & CEX & $\mathrm{SCF}$ \\
\hline$\%$ of Households & 1 & 1 & 0.51 & 0.50 & 0.29 & 0.31 & 0.20 & 0.19 \\
\hline Average Age & 41.2 & 39.6 & 41.8 & 40.5 & 41.8 & 40.8 & 38.7 & 35.5 \\
\hline \% College Degree & 0.45 & 0.39 & 0.59 & 0.53 & 0.37 & 0.30 & 0.22 & 0.17 \\
\hline \% Homeowners & 0.71 & 0.59 & 0.84 & 0.74 & 1.00 & 0.70 & 0.00 & 0.06 \\
\hline Average $U_{i, t}$ & 0.08 & 0.06 & 0.06 & 0.04 & 0.09 & 0.08 & 0.12 & 0.12 \\
\hline Median Income (000's) & 50 & 54 & 69 & 80 & 44 & 48 & 23 & 23 \\
\hline
\end{tabular}

Notes: SCF data is from Kaplan, Moll and Violante (2018) for the 2004 survey. In both surveys I define households as hand-to-mouth if their liquid asset holdings are below the median level. In the SCF, I define households as wealthy if their illiquid asset holdings are above the 25th percentile. The CEX sample uses households in the survey between 2003 and 2005. All statistics are calculated using sampling weights.

unemployed). I sum this within a quarter. Consequently, my quarterly hours growth measure is annual growth in quarterly hours worked.

\section{B Asset Groups: Descriptive Statistics}

Table 8 reports some descriptive statistics about the CEX sample and compares it to households from the Survey of Consumer Finances, where liquid and illiquid asset holdings are measured more accurately. In the SCF, I define households as hand-to-mouth if their liquid asset holdings are below the median value. I then define them as poor hand-to-mouth if their illiquid asset holdings are also below the 25th percentile, and wealthy hand-to-mouth if their illiquid asset holdings are above the 25 th percentile.

In both the CEX and SCF, poor hand-to-mouth households are slightly younger, less likely to have a college degree, and more likely to be unemployed than either non hand-to-mouth or wealthy hand-to-mouth households. Table 8 also shows that housing status is a good proxy for illiquid asset holdings: $70 \%$ of wealthy hand-to-mouth households in the SCF are homeowners, compared to only $6 \%$ of poor hand-to-mouth households. By construction these values are $100 \%$ and $0 \%$ in the CEX. 


\section{Table 9: Consumption Response to Unemployment Spells}

\begin{tabular}{lccccc}
\hline & \multicolumn{2}{c}{ Data $(\mathrm{CEX})$} & & \multicolumn{2}{c}{ One-Asset Model } \\
\cline { 2 - 3 } \cline { 6 - 6 } & $(1)$ & $(2)$ & & $(3)$ & $(4)$ \\
\hline$U_{i, t}$ & -0.22 & -0.31 & & -0.33 & \\
$U_{i, t} \mathbb{1}\{\mathrm{N}-\mathrm{HTM}\}$ & $(0.015)$ & $(0.017)$ & & -0.06 \\
$U_{i, t} \mathbb{1}\{\mathrm{HTM}\}$ & & & & -0.42 \\
\hline Fixed effects & & & & & \\
Control variables & $\checkmark$ & $\checkmark$ & & \\
\hline
\end{tabular}

Notes: Robust standard errors in parentheses. Regressions weighted using CEX sampling weights, with 31638 observations from 1996 to 2017.

\section{Consumption Response to Unemployment Spells}

In this section I provide further evidence on the consumption response to unemployment spells. Column (1) of Table 9 repeats the average response shown in Table 1. The second column removes the control variables to show their importance. Without the control variables, the consumption response to unemployment is biased due to a correlation between unemployment and other demographic characteristics that predict lower consumption. For example, even when employed, the consumption of wealthy and poor hand-to-mouth households is around $10 \%$ and $20 \%$ lower than that of non hand-to-mouth households, respectively.

Finally, columns (3) and (4) repeat the basic regressions in the one-asset model studied in Section 7. Column (3) shows that the one-asset model over-predicts the consumption decline during unemployment. Column (4) shows that this is entirely driven by the hand-to-mouth households in the model, as the one-asset model actually under-predicts the consumption decline for non hand-to-mouth households (who hold too many liquid assets relative to the data).

\section{Income Response to Unemployment Spells}

To estimate whether or not a household's asset status is related to the size of the labor income decline that they experience during an unemployment spell, I estimate equations 2.1 and 2.2 using household wage and salary income as the dependent variable. To focus 
on households whose primary source of labor income is wages and salaries, I restrict the sample to households whose wage and salary income is at least $\$ 7000$ in 2017 prices. Table 10 reports the estimated coefficients for the three versions of the regression used in Section 2. I find that there is no significant difference in the impact of unemployment on labor income across the three groups.

As an alternative to the above, I have used data from the Displaced Worker Supplement of the CPS to estimate how the log change in weekly earnings or length of an unemployment spell after a job displacement vary with education, home ownership, and age. On average, weekly earnings decline by $7.9 \%$ after a job displacement and individuals spend 12.2 weeks unemployed before finding a new job. Table 11 shows that there is no significant effect of education or homeownership on either of the dependent variables. The one characteristic which is associated with both longer unemployment spells and larger earnings declines, is age.

Given that poor hand-to-mouth households tend to be younger than either the non handto-mouth or wealthy hand-to-mouth, this suggests that, if anything, the long-term impact of unemployment spells is smallest for the poor hand-to-mouth. Consequently, this cannot explain the finding that the consumption response is largest for this group.

\section{E Unemployment and Income Risk}

In this section I explain the details behind the decomposition of income growth into hours growth and wage growth used in Section 6.1. I also show that income risk responds endogenously to identified macroeconomic shocks through the effect that these shocks have on unemployment.

The March supplement of the CPS contains annual data on income and hours worked. Using this data, I can decompose income into hours worked and hourly earnings as follows:

$$
y_{i, t}=\underbrace{\left(\frac{y_{i, t}}{h_{i, t}}\right)}_{w_{i, t}} h_{i, t}
$$

where $y_{i, t}$ is the income of individual $i$ in year $t$, and $h_{i, t}$ is the number of hours worked by individual $i$ in year $t$. Consequently, $w_{i, t}$ is a measure of hourly earnings. Taking log differ- 


\section{Table 10: Income Response to Unemployment Spells}

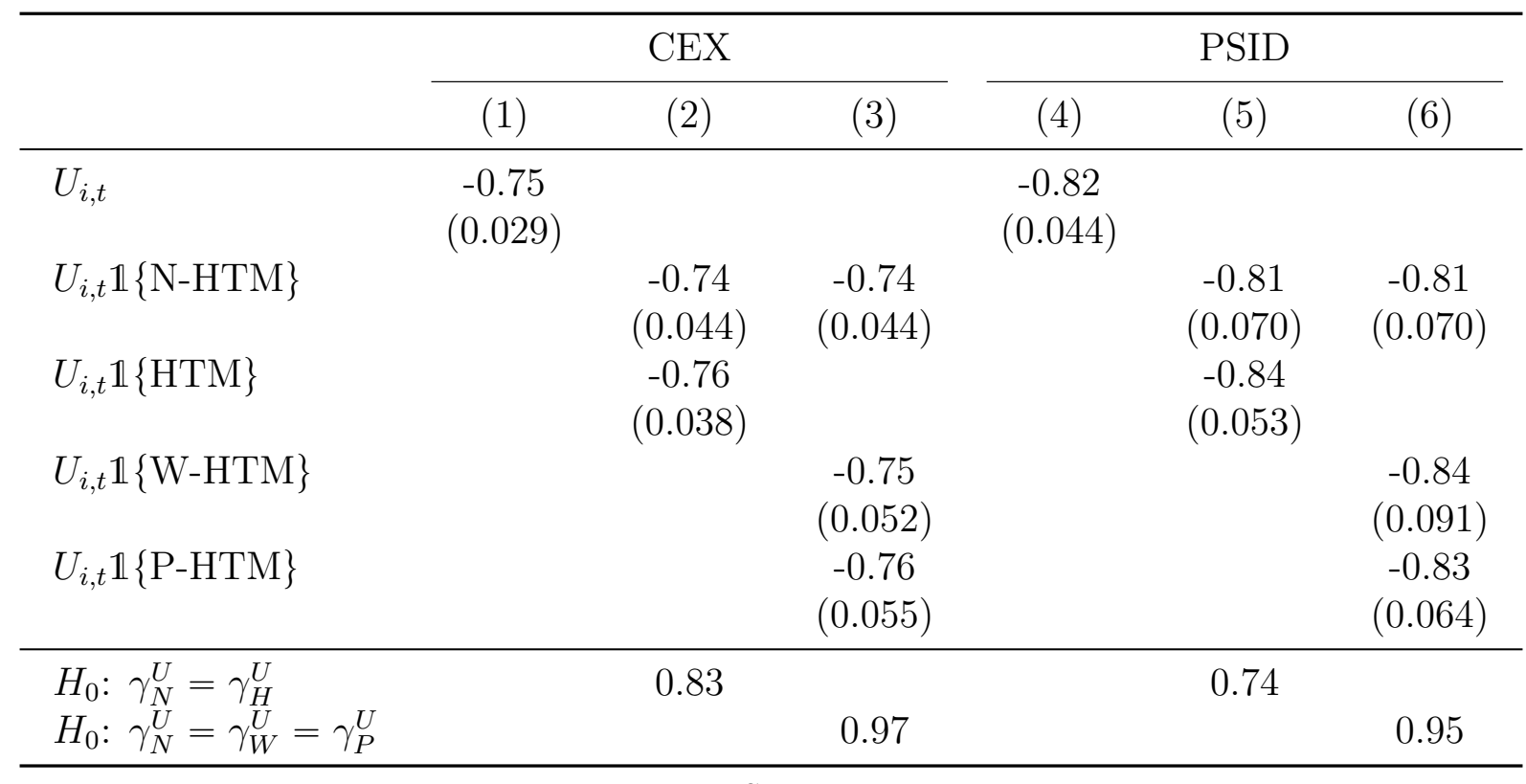

Notes: Robust standard errors in parentheses. PSID standard errors are clustered by household head. Regressions weighted using sampling weights. Final three rows of the table report the p-values for different Wald tests. CEX uses 23218 observations from 1996-2017. PSID uses 22672 observations from 2005-2017.

\section{Table 11: Effect of Job Displacement in the CPS}

\begin{tabular}{lcc}
\hline & $\Delta \log$ Weekly Earnings & Weeks Unemployed \\
\hline Intercept & $0.23^{* * *}$ & $3.61^{* * *}$ \\
& $(0.04)$ & $(1.20)$ \\
$\mathbb{1}\{$ High School $\}$ & -0.004 & -1.26 \\
& $(0.02)$ & $(0.78)$ \\
$\mathbb{1}\{$ Some College & -0.010 & -0.77 \\
& $(0.02)$ & $(0.79)$ \\
$\mathbb{1}\{$ College & 0.017 & -0.33 \\
& $(0.02)$ & $(0.80)$ \\
$\mathbb{1}\{$ Homeowner $\}$ & -0.004 & -0.49 \\
Age $_{i}$ & $(0.01)$ & $(0.45)$ \\
& $-0.008^{* * *}$ & $0.25^{* * *}$ \\
\hline \hline
\end{tabular}

Notes: Robust standard errors in parentheses. Asterisks denote statistical significance at the ${ }^{* * *} 1$ percent, ${ }^{* *} 5$ percent, and ${ }^{*} 10$ percent levels. The sample is restricted to men between the ages of 25 and 55 . Regressions use sampling weights, with 7094 observations from 1990 to 2018. 
ences, income growth can then be decomposed into wage growth and hours growth:

$$
\Delta y_{i, t}=\Delta w_{i, t}+\Delta h_{i, t}
$$

Figure 6 shows a measure of the skewness of the income growth, wage growth, and hours growth distributions over time. ${ }^{27}$ It is clear that the skewness of hours growth drives that of income growth, while the skewness of wage growth changes little over the business cycle. Income growth becomes negatively skewed in recessions because it becomes much more likely to experience a large decline in hours, i.e. to become unemployed. Meanwhile, for those who remain employed, the skewness of the wage growth distribution is unaffected by business cycles. $^{28}$

To show that it is the extensive margin rather than the intensive margin that drives these results (i.e. unemployment rather than average hours worked) Figure 11 plots the income growth distribution in 2006 and 2009 for two groups of individuals: those who experienced unemployment spells in either of the two years used to measure income growth, and those who did not. It is clear from these densities that the the decline in the skewness of the income growth distribution between these two years comes entirely from those households who experienced unemployment spells. In 2009 such households were far more likely to see a large decline in income than in 2006.

Figure 12 plots the skewness of income growth for the entire sample of individuals as well as the sub-samples of individuals that either did or did not experience an unemployment spell. This confirms that the group of individuals with unemployment spells drives the cyclicality of the skewness of the income growth distribution. Finally, Figure 13 plots the skewness of income growth measured in the CPS against the equivalent measure from Guvenen, Ozkan and Song (2014), which uses Social Security Administration data. There is a close correlation between the two series, although the skewness of income growth declines by more in the Social Security Administration data in the past two recessions.

\footnotetext{
${ }^{27}$ Due to the 4-8-4 structure of the CPS, individuals that are in the March survey for the first time in one year should also be interviewed in the March survey in the following year. There are two breaks in my skewness measures which correspond to periods where the CPS identifiers are not consistent across the two interview spells.

${ }^{28}$ Hoffmann and Malacrino (2019) shows similar results using Italian data.
} 
Figure 11: Income Growth Densities and Unemployment Spells
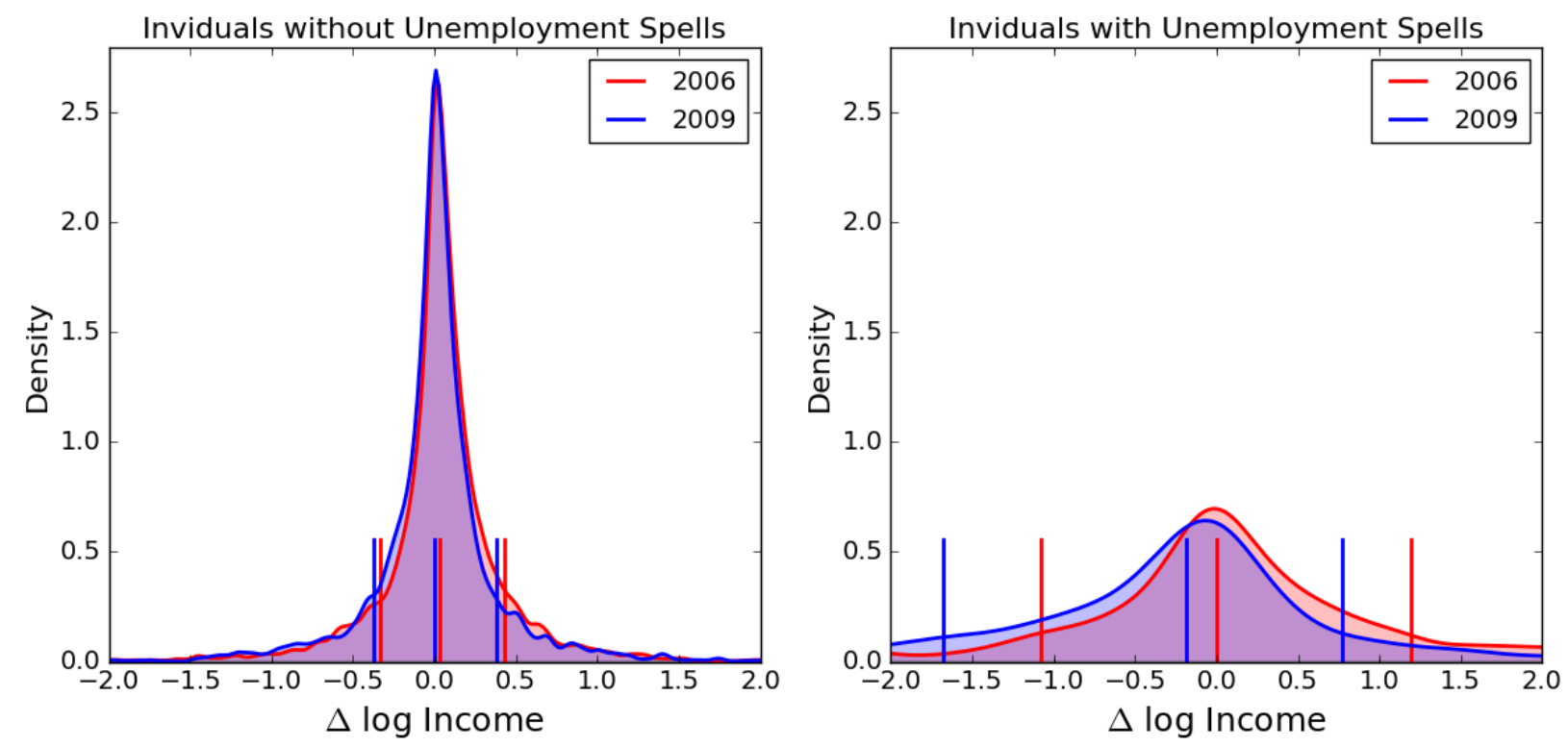

Notes: The vertical lines denote the 10th, 50th, and 90th percentiles of the distribution.

Figure 12: Unemployment Drives Skewness of Income Growth

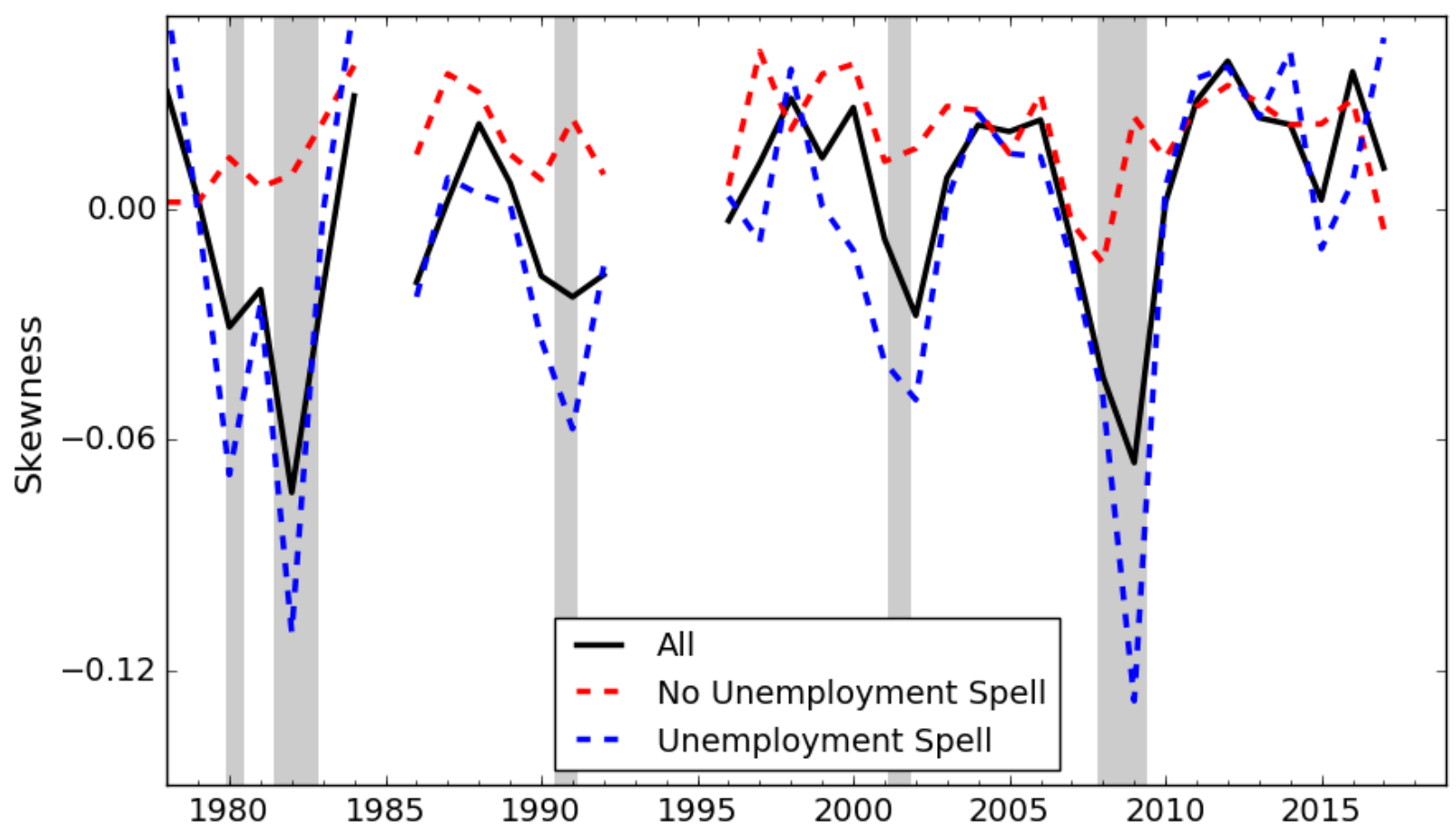

Notes: Skewness measured using Pearson's second skewness coefficient (median skewness). 
Figure 13: Income Skewness: CPS vs. Social Security Data

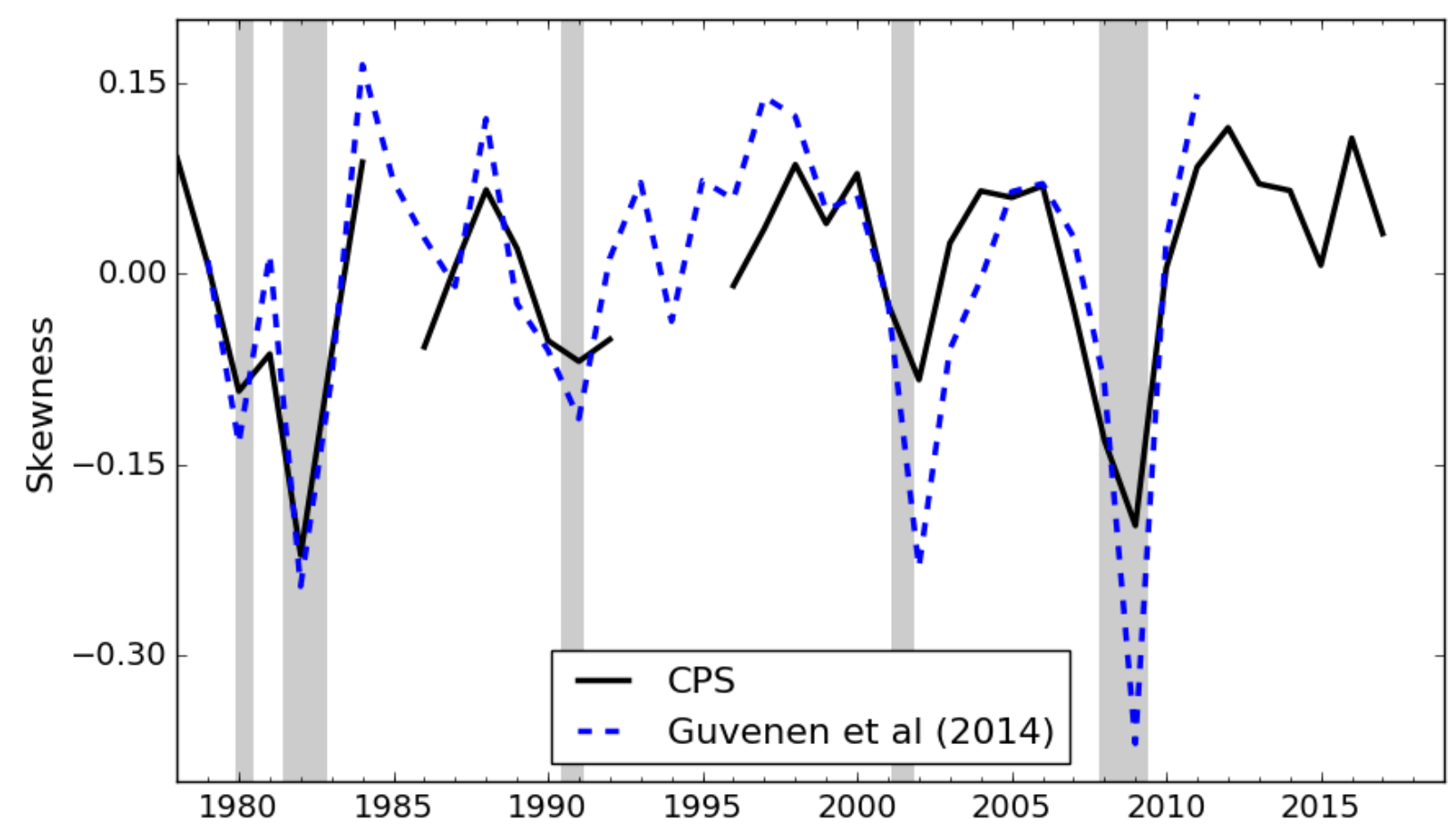

Notes: Skewness measured using Pearson's second skewness coefficient (median skewness).

Figure 14: Quarterly Measures of Skewness

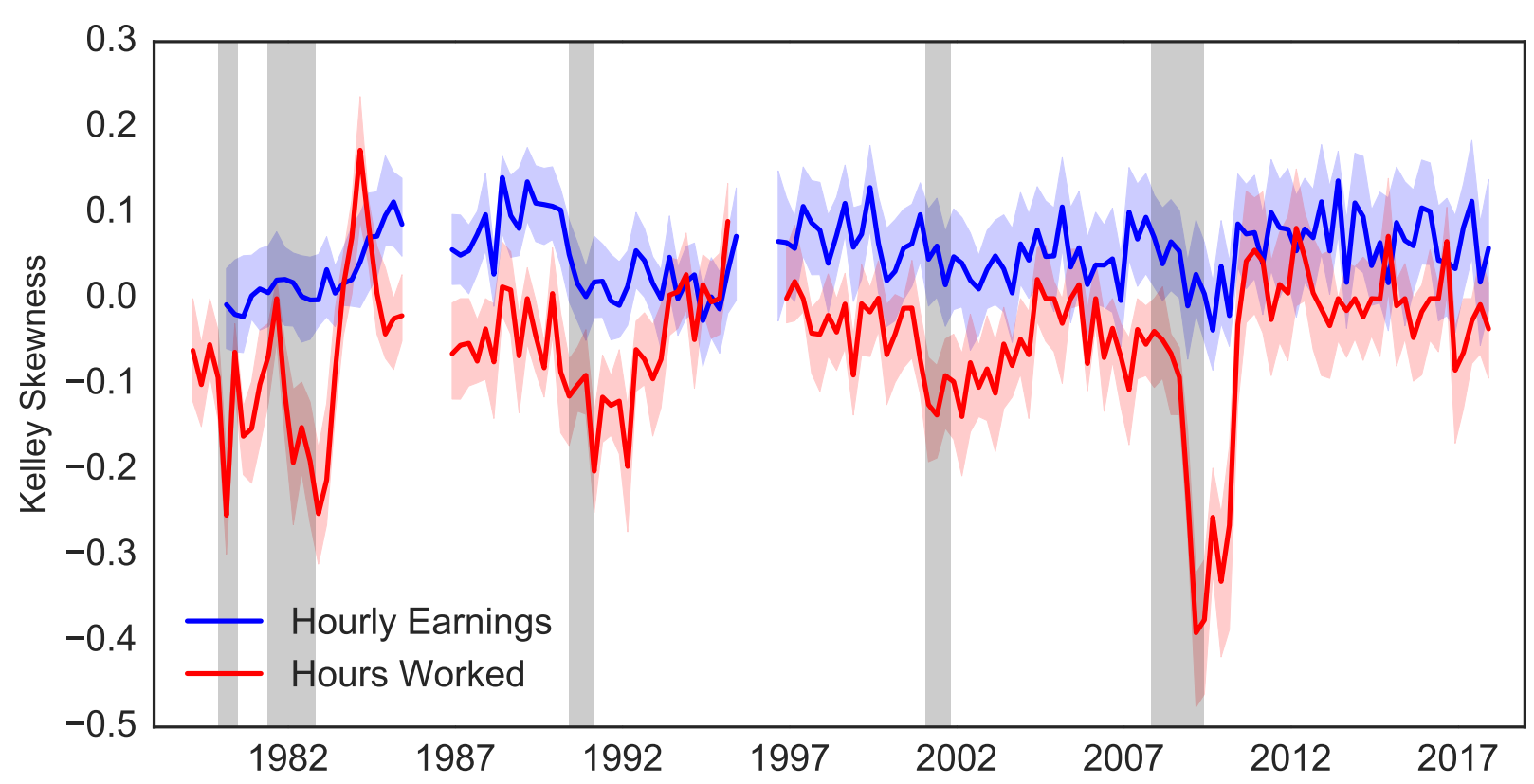

Notes: Skewness measured using Kelley's measure of skewness. 
Figure 15: Response to Monetary Policy and EBP Shocks
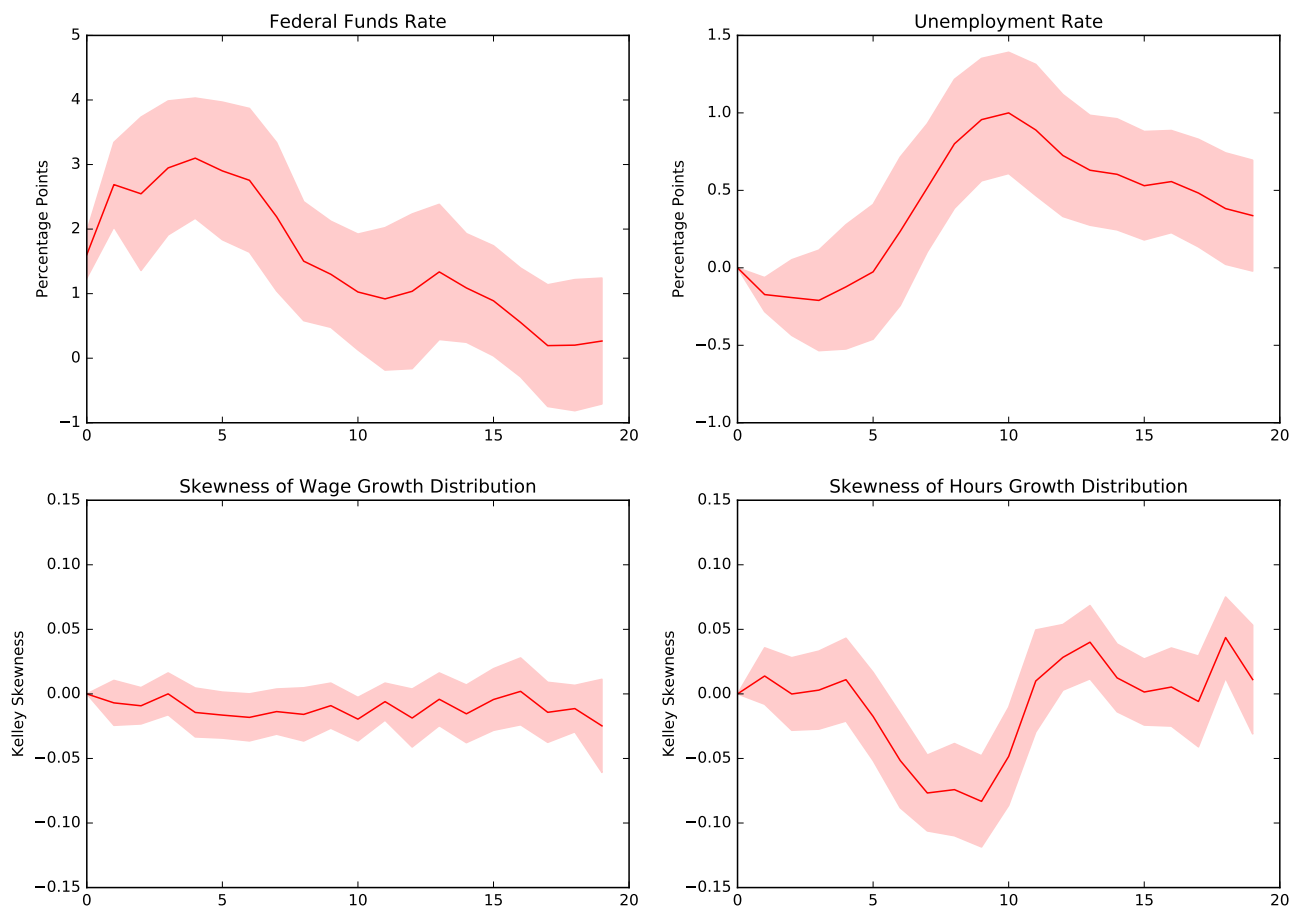

(a) Monetary Policy Shock
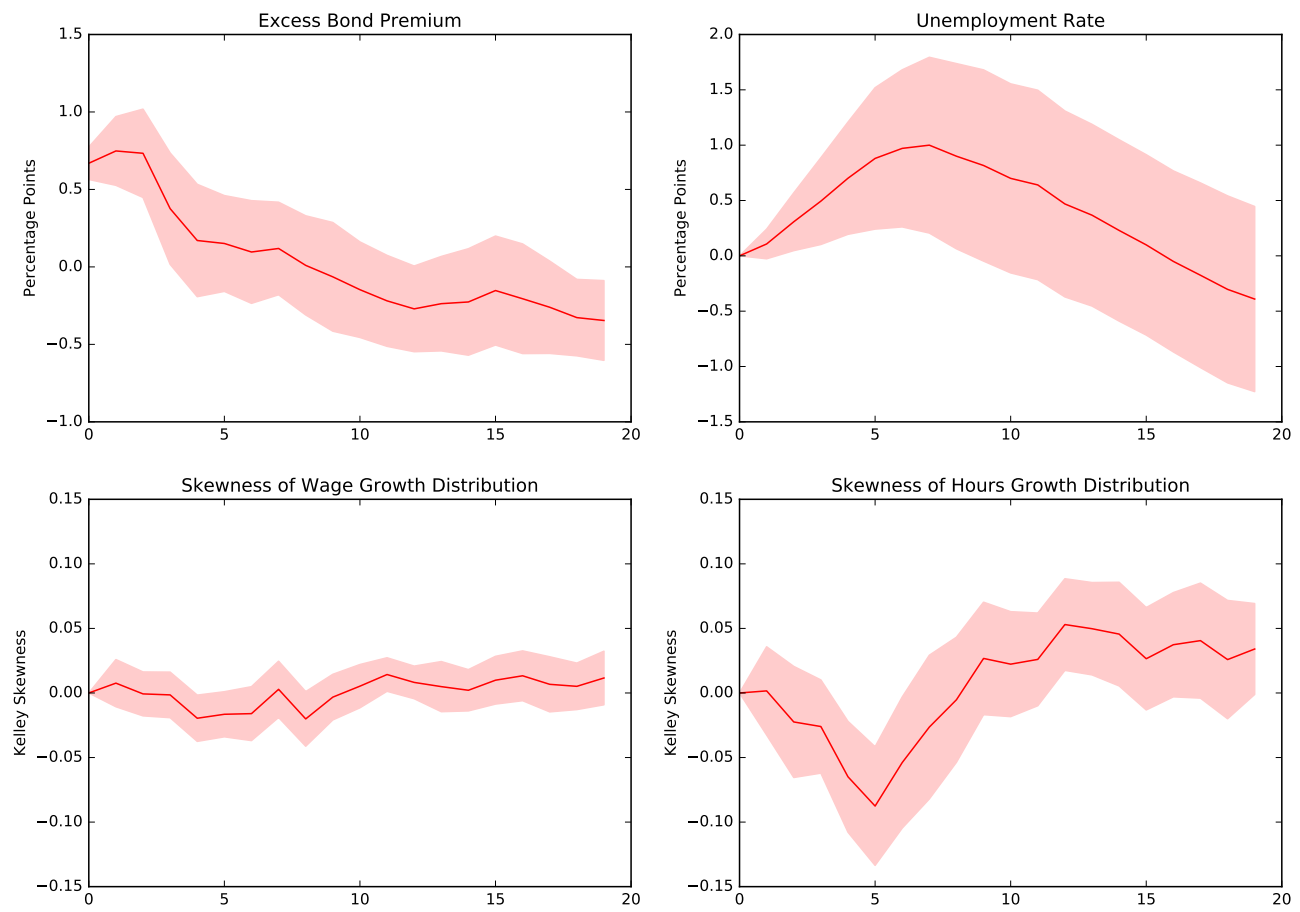

(b) Excess Bond Premium Shock

Notes: Shaded area shows a 95\% confidence interval construct using robust standard errors. Skewness measured using Kelley's measure of skewness. 


\section{E.1 Response of Income Risk to Macroeconomic Shocks}

In this section, I construct measures of hours and wage growth at a quarterly frequency and then estimate the responsiveness of the skewness of these distributions to monetary policy shocks, identified as in Christina D Romer and David H Romer (2004), ${ }^{29}$ and excess bond premium (EBP) shocks, identified using by Simon Gilchrist and Egon Zakrajšek (2012). Figure 14 plots the quarterly estimates of the skewness of hours and wage growth. Due to the small sample size, I use the Kelley skewness measure. ${ }^{30}$

In both cases, I use a local projection approach ${ }^{31}$ to estimate the effect of the shocks on the skewness of the wage and hours growth distributions at different horizons:

$$
Y_{t+h}=\alpha_{h}+\psi_{h}(L) X_{t-1}+\beta_{h} \epsilon_{t}+\zeta_{t+h}
$$

where $\epsilon_{t}$ is the identified shock at time $t, X_{t-1}$ is a vector of control variables and $Y_{t+h}$ is the variable of interest at period $t+h$.

Figure 15a shows the estimated response of the federal funds rate, the unemployment rate, and the skewness of the wage growth and hours growth distributions to a monetary policy shock, and Figure 15b shows the estimated responses to an excess bond premium shock. In both cases, the skewness of the wage growth distribution is unaffected by the shock, while the skewness of the hours growth distribution moves pro-cyclically. This provides further evidence that the income growth distribution is endogenous to macroeconomic shocks, and that this endogeneity is driven by unemployment risk.

\section{F Solving the 2-asset Model}

\section{F.1 Solving the Household Problem}

Solving equation 4.1 numerically involves a significantly higher computational burden than the corresponding problem when the household does not adjust their illiquid asset hold-

\footnotetext{
${ }^{29}$ Extended to 2008 by Olivier Coibion, Yuriy Gorodnichenko, Lorenz Kueng and John Silvia (2017).

${ }^{30}$ Kelley Skewness is equal to $((\mathrm{P} 90-\mathrm{P} 50)-(\mathrm{P} 50-\mathrm{P} 10)) /(\mathrm{P} 90-\mathrm{P} 10)$ where P90/P50/P10 are the $90 \mathrm{th} / 50 \mathrm{th} / 10$ th percentiles of the distribution. This measure of skewness that is robust to outliers and is bounded by -1 and 1.

${ }^{31}$ As in Òscar Jordà (2005).
} 
ings, as the household has a two-dimensional maximization problem (rather than a onedimensional problem that can easily be solved using the golden-section search method).

A robust but slow method for solving equation 4.1 is a nested golden-section search algorithm, in which the maximization over one asset is done in an outer loop, and the maximization over the other asset is done in an inner loop. However, this method is too slow for calculating the response of the economy to aggregate shocks, which requires solving a modified version of equation 4.1 for a large number of periods, multiple times.

A faster method is to break equation 4.1 down into two simpler problems. Specifically, I first solve the problem for households that choose not to adjust their illiquid asset holdings, shown in equation 4.4 .

It is then possible to solve the full problem in equation 4.1 by solving the following onedimensional maximization:

$$
\begin{aligned}
V_{t}^{A}(b, k, z, e) & =\max _{k^{\prime}} V_{t}^{N A}\left(b^{*}, k^{\prime}, z, e\right) \\
\text { subject to } & \\
b^{*} & =\frac{R_{t}^{b}(b) b+R_{t}^{k}\left(k-k^{\prime}\right)}{R_{t}^{b}\left(b^{*}\right)}
\end{aligned}
$$

To see why this works, consider the budget constraint of the problem given by $V_{t}^{N A}\left(b^{*}, k^{\prime}, z, e\right)$ :

$$
k^{\prime}+b^{\prime}+c=\mathbb{1}\{e=1\} w_{t} z(1-\tau)+\mathbb{1}\{e=0\} w_{t} \phi(z)(1-\tau)+T_{t}+R_{t}^{b}(b) b^{*}+R_{t}^{k} k^{\prime}
$$

Now, substitute in the value of $b^{*}$ given in equation F.1:

$$
\begin{aligned}
k^{\prime}+b^{\prime}+c & =\mathbb{1}\{e=1\} w_{t} z(1-\tau)+\mathbb{1}\{e=0\} w_{t} \phi(z)(1-\tau)+T_{t}+R_{t}^{b}\left(b^{*}\right) b^{*}+R_{t}^{k} k^{\prime} \\
& =\mathbb{1}\{e=1\} w_{t} z(1-\tau)+\mathbb{1}\{e=0\} w_{t} \phi(z)(1-\tau)+T_{t}+R_{t}^{b}(b) b+R_{t}^{k}\left(k-k^{\prime}\right)+R_{t}^{k} k^{\prime} \\
& =\mathbb{1}\{e=1\} w_{t} z(1-\tau)+\mathbb{1}\{e=0\} w_{t} \phi(z)(1-\tau)+T_{t}+R_{t}^{b}(b) b+R_{t}^{k} k
\end{aligned}
$$

Thus, the problem in equation F.1 satisfies the household's budget constraint, regardless of the choice of $k^{\prime}$. The adjustment to liquid asset holdings in $b^{*}$ takes into account all effects of the capital adjustment on the household's budget constraint. As equation 4.4 and equation F.1 are relatively simple one-dimensional maximization problems, this significantly increase 
the speed of solving the full problem in equation 4.1.

\section{F.2 Solving for the Steady-State of the Model}

Since I assume that the equilibrium real interest rate is $1 \%$ on an annual basis, and that the steady-state unemployment rate must be $6 \%$, the algorithm for finding the steady-state is as follows:

1. Guess the equilibrium level of capital, $K$.

2. The equilibrium unemployment rate implies an equilibrium labor-market tightness, $\theta$, and value of $h$. Find the steady-state wage that is consistent with this using the steady-state FOC for the labor agency:

$$
\beta\left(h-\bar{w}+\frac{c}{q(\theta)}(1-s)\right)=\frac{c}{q(\theta)}
$$

(Taking into account the calibrated relationship between $c$ and $\bar{w}$.)

3. Given this wage and the job-finding probability, solve the household's problem.

4. Use non-stochastic simulation to find the equilibrium distribution of households.

5. Update the guess of $K$ and return to Step 2.

\section{F.3 Solving the Response to an Aggregate Shock}

In Section 4, I solve the response of the model to an unanticipated aggregate productivity shock. The algorithm for solving for the equilibrium path in response to this shock is described below:

1. Guess paths for the real interest rate and capital stock: $\left\{r_{t}^{b}\right\}_{t=1}^{T}$ and $\left\{K_{t}\right\}_{t=1}^{T}$ (where $T$ is large enough that the economy has returned to the steady-state).

2. Use the Taylor rule and Fisher relation to find the implied path of inflation and the nominal interest rate.

3. Guess a path of employment 
(a) Given the path of employment, calculate the path output using the production function.

(b) Using output and inflation, calculate the path of the mark-up using the New Keynesian Phillips curve.

(c) Using the path of the mark-up, calculate the path of wages.

(d) Using the path of wages, calculate the path of the job-finding rate from the labor agency's Euler equation. Update the guess of the path of employment and return to step $3(\mathrm{a})$.

4. Given the implied paths of the job-finding rate, wage, the real interest rate, and the return on capital, solve the household's problem backwards from $t=T-1$ to 1 .

5. Simulate the household distribution forwards from $t=1$ to $T$.

6. Use the implied paths of liquid asset holdings, $\left\{B^{h}\right\}_{t=1}^{T}$, and capital holdings, $\left\{K_{t}^{h}\right\}_{t=1}^{T}$, to update the guessed path of the real interest rate and capital stock and return to step 2 .

\section{F.4 Consumption-Equivalent Size of Adjustment Costs}

In this section, I calculate the consumption-equivalent size of the illiquid asset adjustment costs in the steady-state of the model. A household that pays adjustment cost $\chi$ and has consumption $C$ would be willing to lower their consumption to $C^{*}$ which satisfies the following equation in order to avoid the adjustment cost:

$$
\frac{C^{*(1-\gamma)}-1}{1-\gamma}=\frac{C^{1-\gamma}-1}{1-\gamma}-\chi
$$

Solving for $C^{*}$ :

$$
C^{*}=\left[C^{1-\gamma}-(1-\gamma) \chi\right]^{\frac{1}{1-\gamma}}
$$

In the calibrated version of the model, $\gamma=2$, so this simplifies to: 


$$
C^{*}=\frac{1}{C^{-1}+\chi}
$$

As the adjustment costs are random, the average level of $C^{*}$ for a household with consumption $C$ whose maximum adjustment cost is $\chi^{*}$ is as follows:

$$
\begin{aligned}
C^{*} & =\frac{1}{\bar{\chi}} \int_{0}^{\chi^{*}} \frac{1}{C^{-1}+\chi} d \chi+\frac{1}{\bar{\chi}} \int_{\chi^{*}}^{\bar{\chi}} \frac{1}{C^{-1}} d \chi \\
& =\frac{1}{\bar{\chi}}\left[\log \left(C^{-1}+\chi^{*}\right)-\log \left(C^{-1}\right)\right]+C \frac{\bar{\chi}-\chi^{*}}{\bar{\chi}}
\end{aligned}
$$

Integrating across households, the total size of adjustment costs in terms of consumption is $\int\left(C-C^{*}\right) d \mu$, which is equal to $1.2 \%$ of total consumption or $0.9 \%$ of total output.

\section{G Robustness}

In this section, I undertake a number of robustness exercises. I show that the main results of the paper are robust to a wide range of values of the wage elasticity $\epsilon_{w}$, that amplification is also present in response to a monetary policy shock, and that amplification relies on price stickiness. I also show that unemployment insurance is a somewhat less effective automatic stabilizer if the lump-sum transfer adjusts to balance the government's budget constraint (rather than government spending) but that unemployment insurance would be even more effective than in the baseline model if all unemployed agents received benefits (rather than only 45\%, as in the data). Finally, I show that if the illiquid asset is housing, rather than physical capital, the model still displays significant amplification through the flight-to-liquidity mechanism.

\section{G.1 Additional IRFs}

Figure 16 provides the impulse response functions for additional variables for the experiment considered in Section 6. 
Figure 16: Response to an Aggregate Productivity Shock
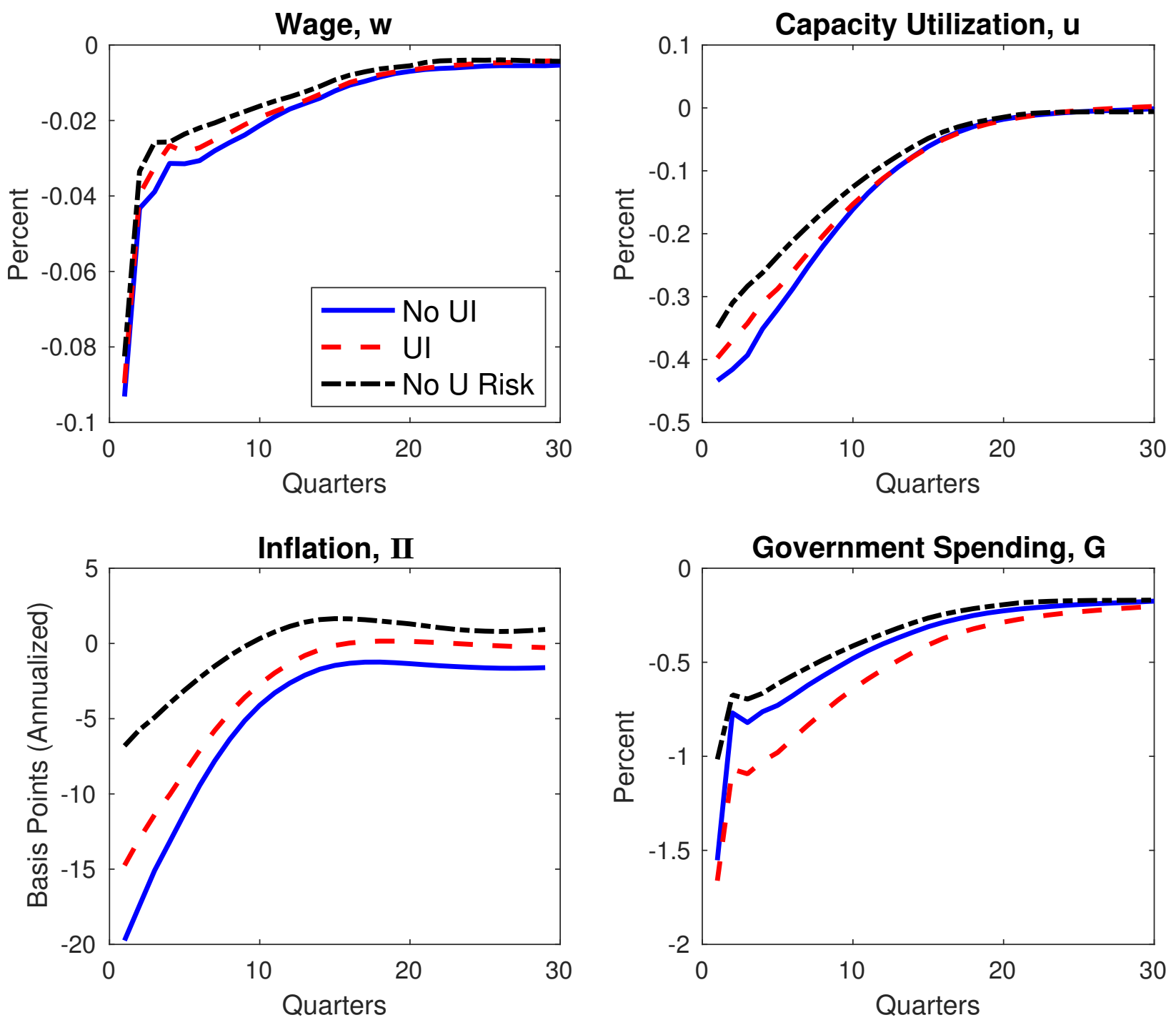

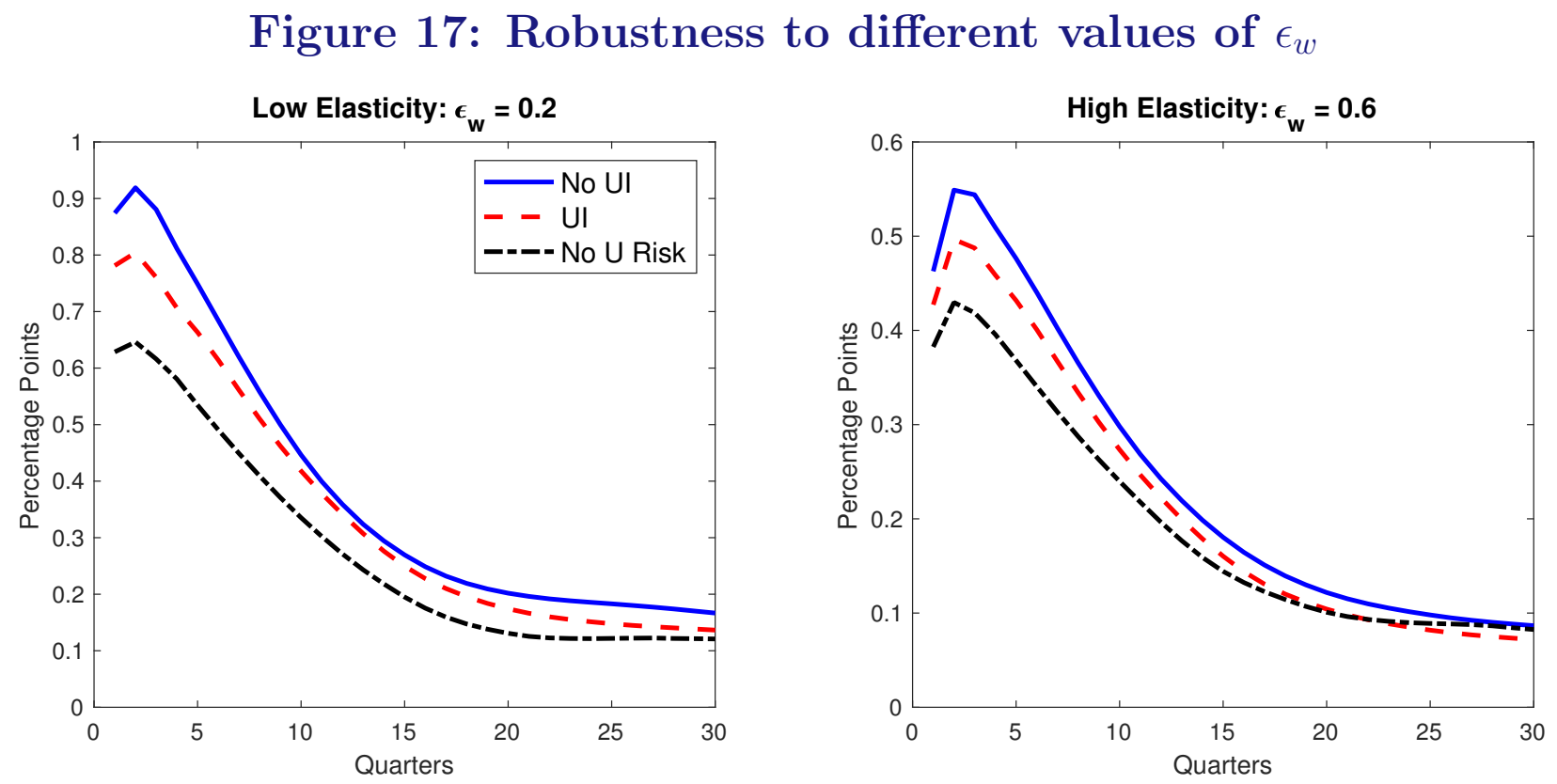

Notes: Percentage point deviation of the unemployment rate from its steady-state value.

\section{G.2 Wage Elasticity}

Due to the complexity of the household problem, it is not possible to use a bargaining solution to determine the equilibrium wage in the models used in this paper. Consequently, I use a wage rule whereby the wage that households receive responds with elasticity $\epsilon_{w}$ to the wage that the labor agency receives from the intermediate good producers.

For the calibration in the main paper, I set $\epsilon_{w}$ to 0.45 (based on the elasticity of real wages to labor productivity documented by Hagedorn and Manovskii (2008)). In this section, I show that the main result of the paper, that unemployment risk significantly amplifies aggregate shocks in the two-asset model, is robust to a wide range of values of $\epsilon_{w}$.

Figure 17 plots the response of unemployment to the aggregate productivity shock when $\epsilon_{w}$ is set to either 0.2 or 0.6 . When the wage that households receive is more flexible, the overall effect of the shock is smaller, as the labor agency are able to pass through more of the decline in wages to households, and consequently the decline in vacancy posting is lessened. However, the amplification that comes from unemployment risk remains: in both cases, the response of unemployment is significantly larger in the model without unemployment insurance when compared to the model with unemployment insurance. 


\section{G.3 Monetary Policy Shock}

Figure 18 plots the response of the three versions of the model to a contractionary monetary policy shock. With this shock, the Taylor rule becomes:

$$
\begin{aligned}
i_{t+1} & =\bar{r}^{b}+\psi \log \left(\Pi_{t}\right)+\epsilon_{m, t} \\
\epsilon_{m, t+1} & =\rho_{m} \epsilon_{m, t}
\end{aligned}
$$

The shock is a 10bp annualized contractionary monetary policy shock $\left(\epsilon_{m, 0}=0.00025\right)$, with persistence $\rho_{m}=0.85$. The amplification caused by idiosyncratic unemployment risk (and the role of unemployment insurance in dampening aggregate volatility) is similar to that seen in Figure 5. This confirms that the presence of idiosyncratic unemployment risk will amplify any aggregate shock which has an effect on the unemployment rate.

\section{G.4 Flexible Prices}

Figure 19 plots the response of the three versions of the model in an economy with flexible prices. If prices are flexible, the effect of the decline in aggregate demand initiated by the rise in unemployment risk is accommodated entirely in prices rather than quantities, and the feedback loop between unemployment risk and aggregate demand is neutralized. Consequently, price rigidity is required for idiosyncratic unemployment risk to lead to business cycle amplification in this model.

\section{G.5 Adjusting $T_{t}$ Not $G_{t}$}

In the experiments considered in Section 6, I assume that government spending adjusts to balance the governments budget constraint each period. In this section, I assume instead that government spending is held constant at its steady-state level, and that the lumpsum transfer adjusts. Figure 20 plots the response of the three versions of the model to the aggregate productivity shock under this assumption. By comparing the versions of the model with no unemployment insurance and no unemployment risk, it is clear that the overall degree of amplification is broadly unchanged under this assumption. However, unemployment insurance is now slightly less effective at reducing the amplification caused 
Figure 18: Response to a Monetary Policy Shock
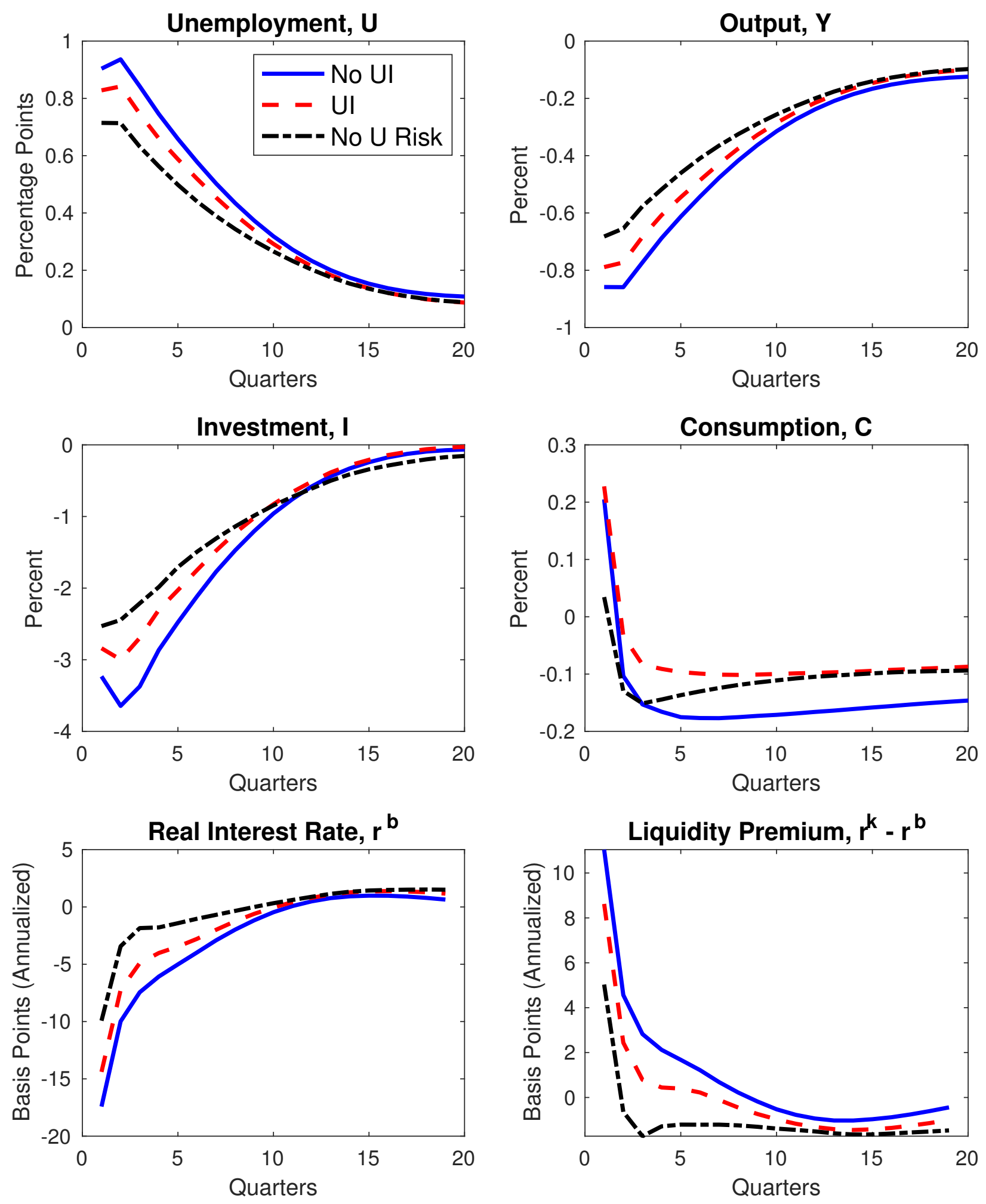
Figure 19: Aggregate Productivity Shock with Flexible Prices
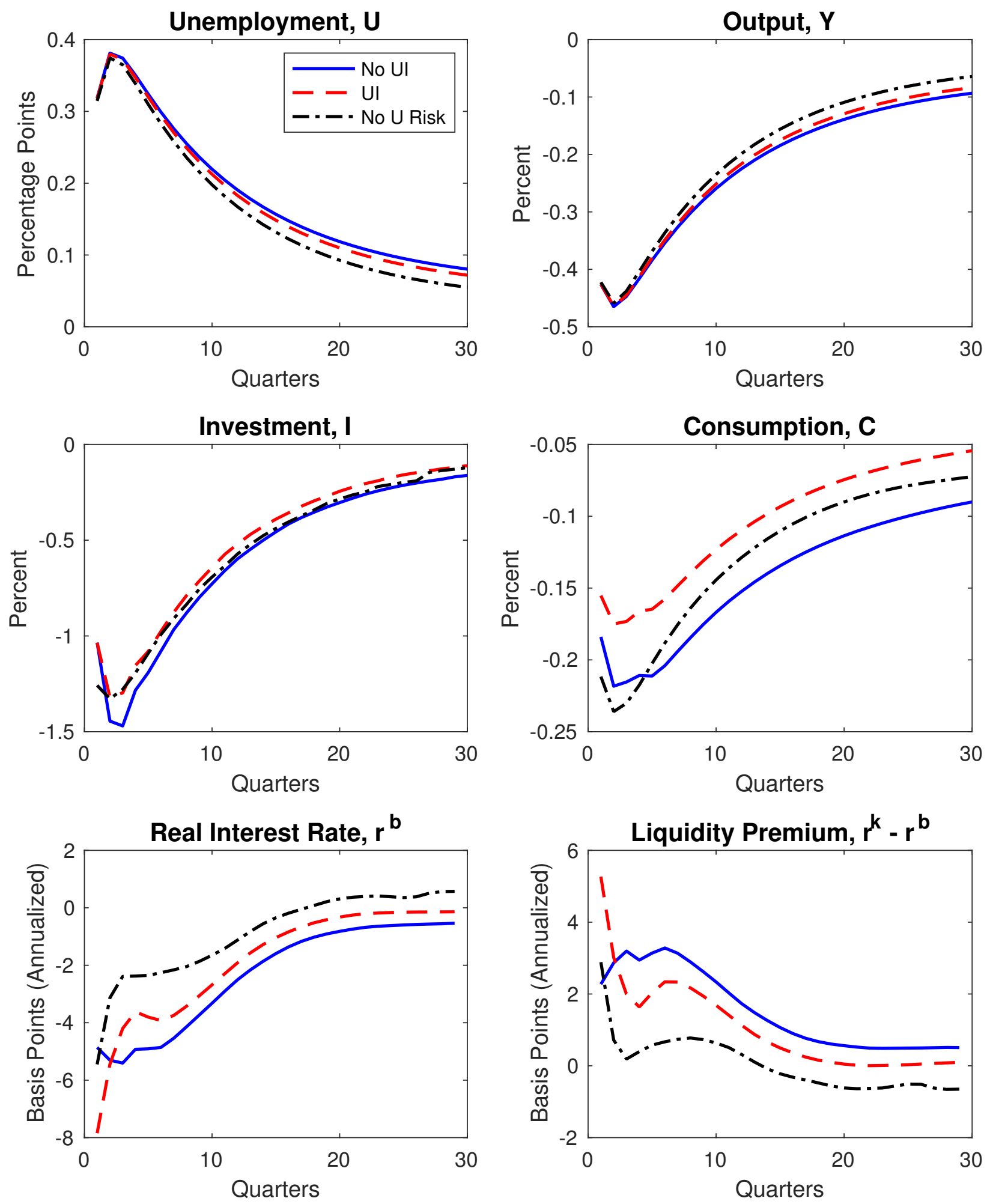
Figure 20: Aggregate Productivity Shock when $T_{t}$ Adjusts
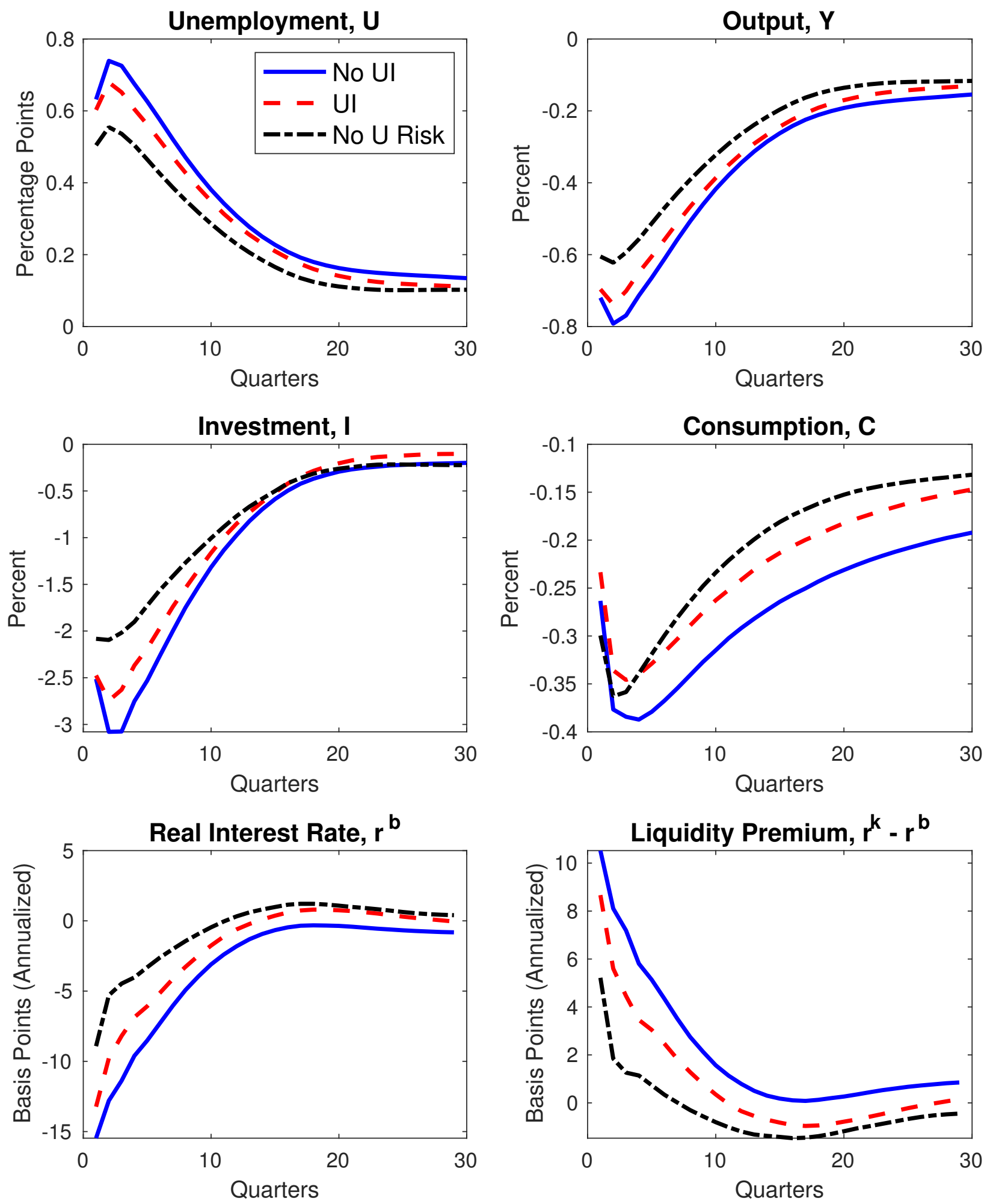
by the flight-to-liquidity mechanism. This occurs as the extra spending on unemployment insurance in response to a rise in unemployment risk is now financed by reducing the lumpsum transfer, rather than by reducing government spending. Consequently, unemployment insurance only redistributes total household income, and no longer supports the level of total household income.

\section{G.6 Expanding Unemployment Insurance Recipiency}

I now consider the impact of raising the unemployment insurance recipiency rate from the baseline level. Figure 21 compares the response to the aggregate productivity shock in the model with no unemployment insurance, with unemployment insurance and $\xi=0.45$ (the baseline calibration), and with unemployment insurance and $\xi=1$.

When $\xi=1$, there is no longer any chance that households become unemployed and receive no unemployment insurance. This reduction in tail-risk further dampens the flightto-liquidity and the feedback loop between unemployment risk and aggregate demand. The model implies that increasing the recipiency rate of unemployment insurance from current levels could significantly reduce business cycle volatility. In fact, the response of the economy to aggregate shocks when $\xi=1$ is quantitatively similar to the version of the model with no idiosyncratic unemployment risk studied in Figure 5. Thus, the two-asset model predicts that ensuring that all unemployed individuals receive unemployment insurance would be sufficient to remove the amplification of aggregate shocks that occurs through the flight-to-liquidity mechanism.

\section{G.7 Housing As the Illiquid Asset}

In this section, I show that the main results of the paper are robust to interpreting the illiquid asset as housing rather than physical capital. The removal of physical capital changes the intermediate good producer problem, as in Section 7. I assume that households receive utility from consumption of the final good and from housing services according to the following utility function:

$$
U(c, h)=\frac{\left(c^{\eta} h^{1-\eta}\right)^{1-\gamma}-1}{1-\gamma}
$$


Figure 21: Effect of Increasing Unemployment Insurance Recipiency
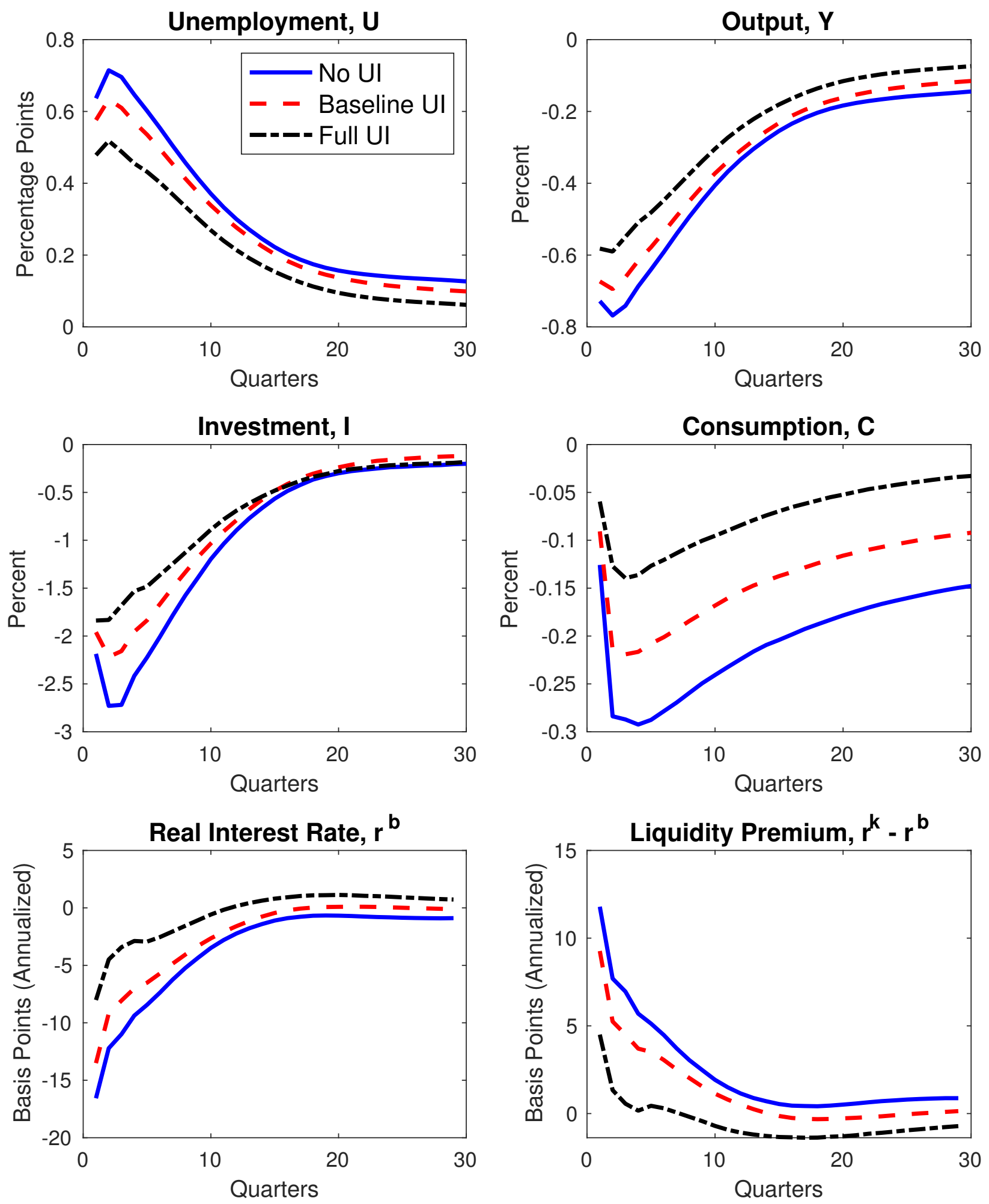
Owner-occupied housing provides a flow of housing services, net of depreciation, equal to $\tilde{r}^{h}=$ $r^{h}-\delta$. Households are also able to purchase rental housing, $c^{h}$. Consequently, consumption of housing services is equal to $h=\tilde{r}^{h} k+c^{h}$. The problem for a household that chooses to adjust their illiquid asset holdings is now:

$$
\begin{aligned}
V_{t}^{A}(b, k, z, e) & =\max _{c, h, b^{\prime}, k^{\prime}} \frac{\left(c^{\eta} h^{1-\eta}\right)^{1-\gamma}}{1-\gamma}+\beta \mathbb{E}_{e^{\prime}, z^{\prime}} V_{t+1}\left(b^{\prime}, k^{\prime}, z^{\prime}, e^{\prime}\right) \\
& \text { subject to } \\
k^{\prime}+b^{\prime}+c+c^{h} & =\mathbb{1}\{e=1\} w_{t} z(1-\tau)+\mathbb{1}\{e=0\} w_{t} \phi(z)(1-\tau)+R_{t}^{b}(b) b+k+T_{t} \\
h & =\tilde{r}^{h} k+c^{h} \\
b^{\prime} & \geqslant-\underline{\mathrm{b}} \\
k^{\prime} & \geqslant 0 \\
z^{\prime} & =\Gamma(z)
\end{aligned}
$$

The goods market clearing condition is:

$$
Y_{t}=C_{t}+C_{t}^{h}+I_{t}+G_{t}+\Theta_{t}+\kappa \int \max \{-b, 0\} d \mu_{t}+c V_{t}
$$

where $C_{t}^{h}$ is the aggregate consumption of rental housing and $I_{t}$ is now residential investment. When solving the model, there is one fewer market clearing condition, as there is no longer a market for physical capital. Consequently, the algorithm to solve the model is similar to that used for the one-asset model. ${ }^{32}$

I recalibrate the model as in Section 7. I assume that $\tilde{r}^{k}$ is equal to the steady-state level of $r^{k}$ in the two-asset model in Section 4 . I lower $\beta$ to 0.97 and $\bar{\chi}$ to 1.5 in order to target the total levels of liquid and illiquid assets relative to GDP. I assume a depreciation rate on housing of 1.5\% per year, as in Greg Kaplan, Kurt Mitman and Giovanni L Violante (2017). Figure 22 shows the response of the economy to the same shock considered in Section 6. The main results are unchanged if the illiquid asset is housing rather than physical capital: a rise in unemployment risk leads to a flight to liquidity and a decline in investment. The only change is that the decline in investment is in housing rather than in physical capital. The amplification that this mechanism provides is roughly unchanged.

\footnotetext{
${ }^{32}$ The treatment of housing in this version of the model is the same as in the NBER working paper version of Kaplan, Moll and Violante (2018).
} 
Figure 22: Aggregate Productivity Shock with Illiquid Housing
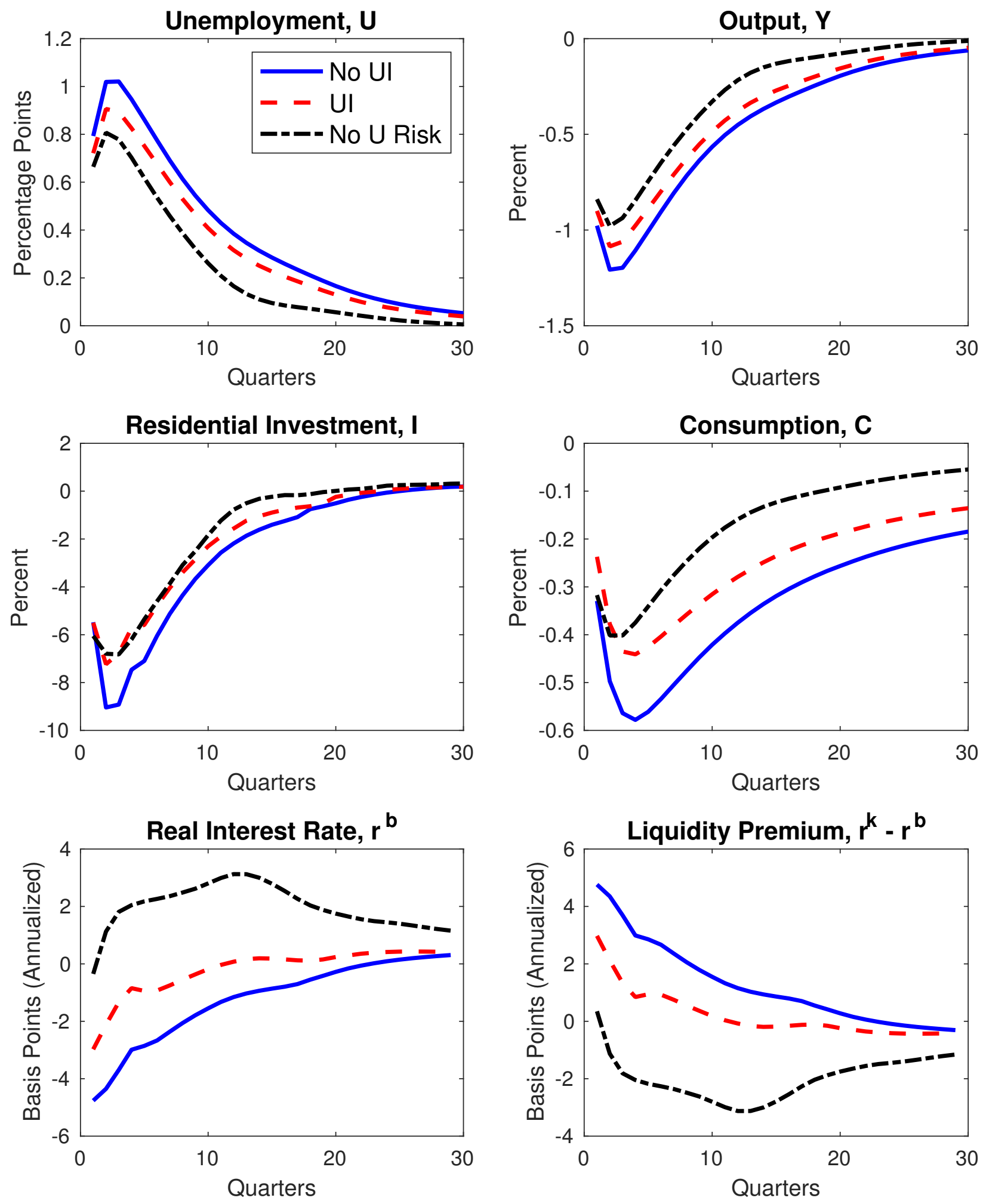